\title{
Quality characteristics of Kujippong (Cudrania tricuspidata) vinegar fermented by various acetic acid bacteria
}

\author{
Su Jeong Lee, Sun Hee Kim, So Young Kim, Soo-Hwan Yeo* \\ Fermented Processing Food Science Division, Department of Agrofood Resource, NAS, RDA, Wanju 55365, Korea
}

\section{초산균 종류에 따른 꾸지뽕 발효식초의 품질 특성}

\author{
이수정 · 김순희 · 김소영 · 여수환* \\ 농촌진흥청 국립농업과학원 농식품자원부 발효가공식품과
}

\begin{abstract}
In this study was we investigated the optimum conditions for the fermentation of Kujippong (Cudrania tricuspidata) vinegar by various acetic acid bacteria (Acetobacter pasteurianus A26, A37, B7) and its quality characteristics. Fermentation at various initial acidities $(\mathrm{pH} 2,3$, and 4$)$ and temperatures $\left(20^{\circ} \mathrm{C}, 30^{\circ} \mathrm{C}\right.$, and $\left.35^{\circ} \mathrm{C}\right)$ revealed that A. pasteurianus $\mathrm{A37}$ and $\mathrm{B} 7$ produced the most acetic acid when fermented at $\mathrm{pH} 4$ and $20^{\circ} \mathrm{C}$. The acidities of the Kujippong fermented vinegars prepared with the A37 and B7 strains increased by $6.3 \%$ and $6.1 \%$, to $\mathrm{pH} 2.45$ and $\mathrm{pH}$ 2.43, respectively. Meanwhile, the vinegar produced by the A26 strain showed low acidity under all conditions. At the end of fermentation period, the acetic acid content of the main organic acid had increased by a factor of ten from day 0 , to values of $37.34 \mathrm{mg} / \mathrm{mL}$ for $A$. pasteurianus $\mathrm{A37}$ and $39.34 \mathrm{mg} / \mathrm{mL}$ for $\mathrm{B} 7$. The $\mathrm{A37}$ and B7 strains produced $37.5 \%$ and $\mathbf{5 9 . 2 \%}$ volatile components, respectively, which were mainly acetic acid and its ethyl ester, among a relatively diverse range of volatile compounds produced. Therefore, the good aceitc acid production of farm-made Kujippong-fermented vinegar is expected to promote the consumption of local agricultural products and and increase in farm income.
\end{abstract}

Key words : Kujippong, acetic acid bacteria, farm-made type, fermentation, vinegar

\section{서 론}

발효식품은 미생물의 분해 작용을 통해 식품의 풍미 및 저장성 향상, 식물 섬유소의 활성 증진 등 많은 장점을 가지 고 있어 활용이 증가하고 있다 $(1,2)$. 그 중에서도 식초는 술과 함께 인류의 식생활에서 가장 오랜 역사를 갖는 발효 식품 중의 하나로서, 동서양을 막론하는 대표적인 조미료 로 이용되고 있다(3).

식초의 품질은 원료, 발효법, 제조방법 등에 따라 크게 달라지고, 초산 함량, 유기산 조성 및 맛에 영향을 주는

*Corresponding author. E-mail : yeobio@korea.kr

Phone : 82-63-238-3609, Fax : 82-63-238-3843

Received 24 September 2019; Revised 11 October 2019; Accepted 13 November 2019.

Copyright (c) The Korean Society of Food Preservation. All rights reserved.
유리아미노산 조성 등도 이에 영향을 미친다(4). 이러한 식초는 고유의 식품 방부제 기능 이외에 젖산분해 촉진, 콜레스테롤 저하 및 체지방 감소 등의 기능성 효과가 있는 것으로 밝혀지면서(5) 조미료로서 뿐만 아니라 마시는 건강 음료로서도 다양하게 활용되고 있다.

꾸지뽕(Cudrania tricuspidata)은 뽕나무과에 속하며, 잎 은 뽕잎 대용으로, 나무껍질과 뿌리는 약용이나 종이 원료 로 쓰인다. 그 중 열매는 모양이 둥글고 취과로 지름이 2-3 $\mathrm{cm}$ 인 육질로 9-10월에 붉게 익으며(6), 잼을 만들거나 술을 담그고 한방에서는 청열, 양혈 등의 효능이 있어 약재로 사용되기도 한다(7). 동의보감에서는 강장, 자양, 숙취해소 등의 특성이 있는 것으로 알려져 있다(8). 또한 항균 및 항염증 작용 $(9,10)$, 항당뇨(11), 항산화 작용(12) 등 생리활 성에 대한 다양한 연구가 진행됨에 따라 전라도 지역을 중심으로 재배 면적이 확대되고 있다고 보고되어 있다(13). 그러나 대부분 꾸지뽕나무의 껍질과 잎에 대한 연구와 
더불어 열매 중에서도 생리활성에 관한 연구가 보고되었으 며(14-16), 이를 제외한 꾸지뽕 열매의 발효물질에 대한 연 구 결과는 거의 없는 실정이다. 따라서 본 연구에서는 생리 활성 효능이 우수하다고 알려진 꾸지뽕 열매를 이용한 농가 형 발효식초 제조를 통해 농업자원의 가치를 향상시키고 정치발효에 따른 꾸지뽕 식초의 품질 특성을 규명함으로써 꾸지뽕의 산업적 활용 방안을 제시하고자 한다.

\section{재료 및 방법}

\section{실험재료 및 전처리 방법}

본 연구에 사용한 꾸지뽕(C. tricuspidata) 열매는 2017년 9월 경남 밀양의 농가에서 수확하여 냉동상태로 유통하는 것을 구입하여 사용하였다. 이를 유수에 세척하고 덩어리 지지 않게 파쇄 한 후, 알코올 발효에 적합한 농도를 조절하 기 위해, 총 원료의 $180 \%(\mathrm{v} / \mathrm{v})$ 를 가수하였다. 가수한 착즙 액을 설탕으로 보당 $\left(24{ }^{\circ} \mathrm{Brix}\right)$ 한 후, 식용 ascorbic acid $0.2 \%$ $(\mathrm{w} / \mathrm{v})$ 를 첨가하여 갈변을 억제하였다. 발효 초기에 착즙액 의 잡균번식을 억제시키기 위해 $80^{\circ} \mathrm{C}$ 에서 1 시간 동안 열처 리하여 발효주 제조의 시료로 사용하였다.

\section{사용균주 및 배지조성}

꾸지뽕 발효주를 제조하기 위해 전통주제조에 주로 사용 하는 송천효모(Saccharomyces cerevisiae)와 와인제조에 사 용되는 수입산 건조효모(S. cerevisiae Fermivin)를 이용하 여 알코올 발효시킨 결과, 알코올 생성능이 우수한 송천효 모를 사용하였다(17). 공시균주인 송천효모를 $30^{\circ} \mathrm{C}, 72$ 시간 진탕배양 $(180 \mathrm{rpm})$ 하면서 대수 증식기의 건강한 효모 배양 액을 주모로 사용하였다.

농가형 정치발효 꾸지뽕 식초를 제조하기 위해, 본 연구 팀에서 농가 및 식품 관련 연구소로부터 제공받은 식초에서 산 생성능이 우수한 초산균 3종( $A$ pasteurianus $\mathrm{A} 26$ (KACC 92205P), A37(KACC 92206P), B7(KACC 92207P)) 을 분리·선발하여 국립농업과학원 $\mathrm{KACC}$ 에 등록한 후 사 용하였다. 배지조성은 각각의 초산균 특성에 맞게 $A$ pasteurianus $\mathrm{A} 26$ 균주는 $\mathrm{GYC}$ 배지 $(0.5 \%$ yeast extract, $3 \%$ glucose, $1 \%$ acetic acid, $8 \%$ ethanol)를, $A$ pasteurianus A37 과 $\mathrm{B} 7$ 은 초산균 배지 $(0.5 \%$ yeast extract, $0.5 \%$ glucose, $1 \%$ glycerin, $0.02 \% \mathrm{MgSO}_{4} \cdot 7 \mathrm{H}_{2} \mathrm{O}, 1 \%$ acetic acid, $8 \%$ ethanol)에 서 $30^{\circ} \mathrm{C}, 180 \mathrm{rpm}$ 으로 진탕 배양하여 종초 제조용 종균으로 사용하였다.

\section{알코올 및 초산 발효조건}

상기의 전처리 방법을 통해 제조한 꾸지뽕 착즙액에 송 천효모 배양액 $3 \%(\mathrm{v} / \mathrm{v})$ 을 접종하여 $30^{\circ} \mathrm{C}, 180 \mathrm{rpm}$ 으로 72 시간 진탕 배양하여 주모를 제조하였다. 동일한 전처리조
건으로 제조한 꾸지뽕 착즙액의 $3 \%(\mathrm{v} / \mathrm{v})$ 가 되게 주모를 넣은 후, $25^{\circ} \mathrm{C}, 9$ 일간 알코올 발효를 하였다. 발효주를 증류 수로 희석하여 알코올 $8 \%$ 로 제성한 후, 초산발효를 위한 꾸지뽕 발효주로 사용하였다.

선발한 3종류의 초산균( $A$ pasteurianus $\mathrm{A} 26, \mathrm{~A} 37, \mathrm{~B} 7)$ 을 이용한 종초 제조는 $8 \%$ 로 제성한 꾸지뽕 발효주에 각각의 최적배지에 배양한 초산균 배양액 $10 \%$ (v/v)을 접종 후, 정치배양하면서 적정산도가 3-3.5\%의 종초를 제조하였다.

꾸지뽕 발효식초의 최적조건을 확립하기 위하여 $8 \%$ 로 제성한 꾸지뽕 발효주에 식용 구연산 및 탄산칼슘을 이용하 여 초기 산도(pH 2, 3, 4)로 조절한 후, 서로 다른 발효온도 $\left(20,30,35^{\circ} \mathrm{C}\right)$ 에서 정치발효를 통한 꾸지뽕 발효식초의 최 적 제조조건을 선발하고자 하였다. 따라서 각 초기 산도별 꾸지뽕 발효주에 종초를 각각 $10 \%(\mathrm{v} / \mathrm{v})$ 씩 넣고 발효 온도 별로 정치배양 하면서 6 일 간격으로 30 일간 품질 변화를 모니터링 하였다(Fig. 1).

\section{$\mathrm{pH}$ 및 적정산도}

$\mathrm{pH}$ 는 시료 $20 \mathrm{~mL}$ 을 취하여 $\mathrm{pH}$ meter(Orion $420 \AA$, Waltham, USA)를 이용하여 실온에서 측정하였다. 적정산 도는 시료 $1 \mathrm{~mL}$ 를 채취한 뒤, 증류수 $9 \mathrm{~mL}$ 로 10 배 희석하여 $1 \%$ phenolphthalein solution을 2-3 방울 가하여 $0.1 \mathrm{~N} \mathrm{NaOH}$ 용액으로 중화 적정한 후, 소비된 용액의 양을 acetic acid로 환산하여 \%로 표시하였다.

\section{색 도}

색도는 $10 \mathrm{~mm}$ 셀에 시료 $10 \mathrm{~mL}$ 를 채운 후, 색차계 (UltraScan Pro, HunterLab, Virsinia, USA)를 이용하여 $\mathrm{L}$ (lightness), a(red value), 그리고 b(yellow value) 값으로 나타내었다.

\section{유기산 함량}

유기산 함량은 Beak 등(18)의 방법을 응용하여 분석하였 다. 시료 $10 \mathrm{~mL}$ 를 취하여 $0.2 \mu \mathrm{m}$ membrane filter로 여과한 후, 유기산을 분석하였으며 분석 장비는 HPLC(LC-20A Prominence, Shimadzu Co., Tokyo, Japan)를 사용하고, 칼럼 은 $\mathrm{C}_{18}(250 \times 4.6 \mathrm{~mm}$ id, S-5 $\mu \mathrm{m}, 12 \mathrm{~nm}$; YMC, Kyoto, Japan $)$ 을 사용하였다. 용매로 꾸지뽕 발효주에 $0.1 \%$ phosphoric acid, 식초에 $0.1 \%$ formic acid를 사용하였으며, 유속은 0.6 $\mathrm{mL} / \mathrm{min}$, 주입량은 $20 \mu \mathrm{L}$ 로 분석하였다.

\section{유리 아미노산 함량}

시료 $5 \mathrm{~mL}$ 를 $0.45 \mu \mathrm{m}$ membrane filter로 여과하여 분석에 사용하였으며, 아미노산 분석기는 Sykam의 S7130 amino acid reagent organizer, S5200 sample injector와 S2100 solvent delivery system을 사용하였다. 컬럼은 cation separation 컬럼 LCA K06/NA(250 mm $\times 4.6 \mathrm{~mm})$ 을 사용하 


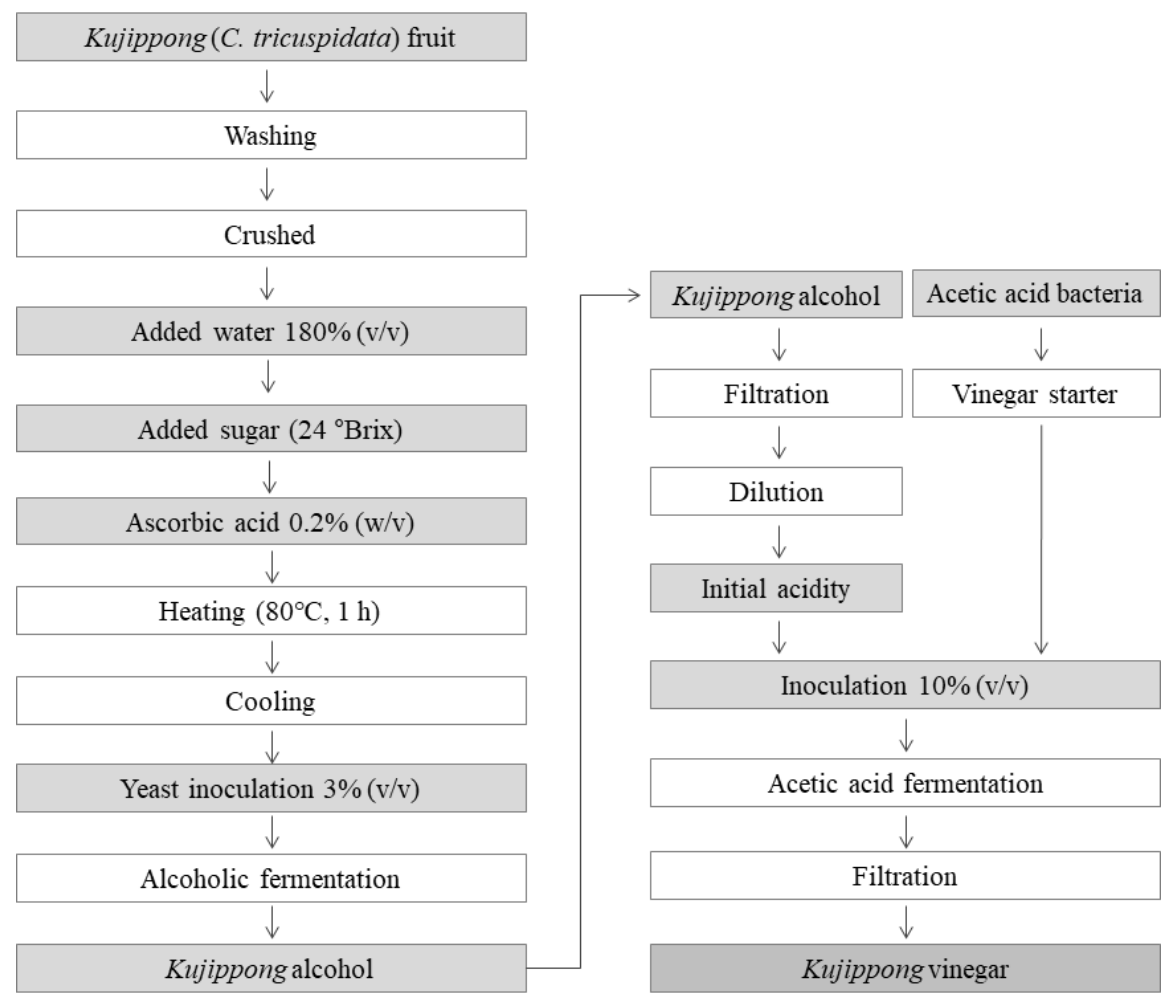

Fig. 1. Manufacturing process of farm-made type Kujippong vinegar.

여 분석하였다. 이동상의 유속은 $0.45 \mathrm{~mL} / \mathrm{min}$, ninhydrin은 $0.4 \mathrm{~mL} / \mathrm{min}$ 로 분석하였다(19).

\section{휘발성 향기성분}

시료 $3 \mathrm{~mL}$ 를 headspace glass vial에 넣은 후, 내부표준물 질로 지정한 2-methyl-1-phentanol을 주입하여 시료가 담긴 headspace용 vial을 $35^{\circ} \mathrm{C}$ 로 30 분간 평형상태에 도달시킨 후, 5 분간 SPME fiber(DVB/CAR/PDMS)를 노출시켜 휘발성 향기성분을 포집하여 $200^{\circ} \mathrm{C} \mathrm{GC/MS}$ injector에서 5 분간 탈 착시켜 휘발성 향기성분을 분석하였다. 분석에 사용한 GC/MS는 GC-2010 Plus, GCMS-TQ 8030(Shimadzu, Tokyo, Japan)을 이용하였으며, 칼럼은 DB-WAX( $30 \mathrm{~mm} \times 0.25 \mathrm{~mm}$ i.d., $0.25 \mu \mathrm{m}$ film thickness, J\&W, CA, USA)를 이용하였다. 승온 프로그램은 $40^{\circ} \mathrm{C}$ 에서 3 분간 머무른 뒤, $5^{\circ} \mathrm{C} / \mathrm{min}$ 의 속 도로 $90^{\circ} \mathrm{C}$ 까지 승온시키며, $19^{\circ} \mathrm{C} / \mathrm{min}$ 의 속도로 $230^{\circ} \mathrm{C}$ 까지 승온시킨 후, 5 분간 유지하였다. 주입 온도는 $250^{\circ} \mathrm{C}$ 로 설정 하였으며, 운반 기체는 $\mathrm{He}$ 을 사용하였고 유속은 1.0 $\mathrm{mL} / \mathrm{min}$ 으로 하였다(20).

\section{통계분석}

시료 분석은 동일 실험을 3 회 반복하여 실시하였으며, 실험군당 평균과 표준편차로 나타내었다. 유기산 및 휘발 성 향기성분은 SAS(Statistical Analysis System 9.4, SAS Institute, INC., Cary, NC, USA) 통계 프로그램을 이용하여
Duncan's multiple range test로 p값이 0.05 미만 수준에서 통계적 유의성을 검토하였다.

\section{결과 및 고찰}

\section{정치발효로 제조한 꾸지뽕 발효식초의 $\mathrm{pH}$ 및 적정산도 의 변화}

꾸지뽕 열매를 이용하여 3종류의 초산균( $A$ pasteurianus $\mathrm{A} 26, \mathrm{~A} 37, \mathrm{~B} 7)$ 으로 제조한 초산 발효물의 발효기간 및 온도 에 따른 $\mathrm{pH}$ 및 적정산도의 변화를 조사하여 Fig. 2에 나타내 었다. 초기 산도를 $\mathrm{pH} 2,3,4$ 로 조절하여 온도별 $(20,30$, $35^{\circ} \mathrm{C}$ )로 초산 발효시킨 결과, $A$ pasteurianus $\mathrm{A} 26$ 을 이용한 꾸지뽕 식초는 초산발효가 제대로 되지 않는 것으로 보아 추가적인 연구가 필요할 것으로 여겨진다.

$\mathrm{A} 37$ 초산균은 초기 $\mathrm{pH}$ 를 높게 설정하고 발효온도가 낮 을수록 꾸지뽕 발효식초의 적정산도가 높은 것을 알 수 있었다(Fig. 2). 초기 $\mathrm{pH}$ 4와 발효온도 $20^{\circ} \mathrm{C}$ 에서 발효 전(미

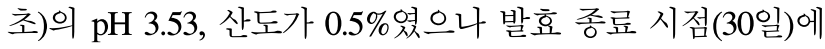
서 $\mathrm{pH} 2.45$, 산도 $6.3 \%$ 로 발효 초기보다 산 생성능이 12.6 배 높았다. A pasteurianus $\mathrm{B} 7$ 또한 동일조건 $\left(\mathrm{pH} 4,20^{\circ} \mathrm{C}\right)$ 에서 발효 전의 $\mathrm{pH} 3.72$, 산도 $0.4 \%$ 였으나 발효 종료 시 $\mathrm{pH} 2.43$, 산도 $6.1 \%$ 로써 A37 초산균과 비슷한 수준의 산 생성능을 유지하였다. 그러나 A37과 B7 초산균은 초기 산도 $\mathrm{pH} 2$ 2에 

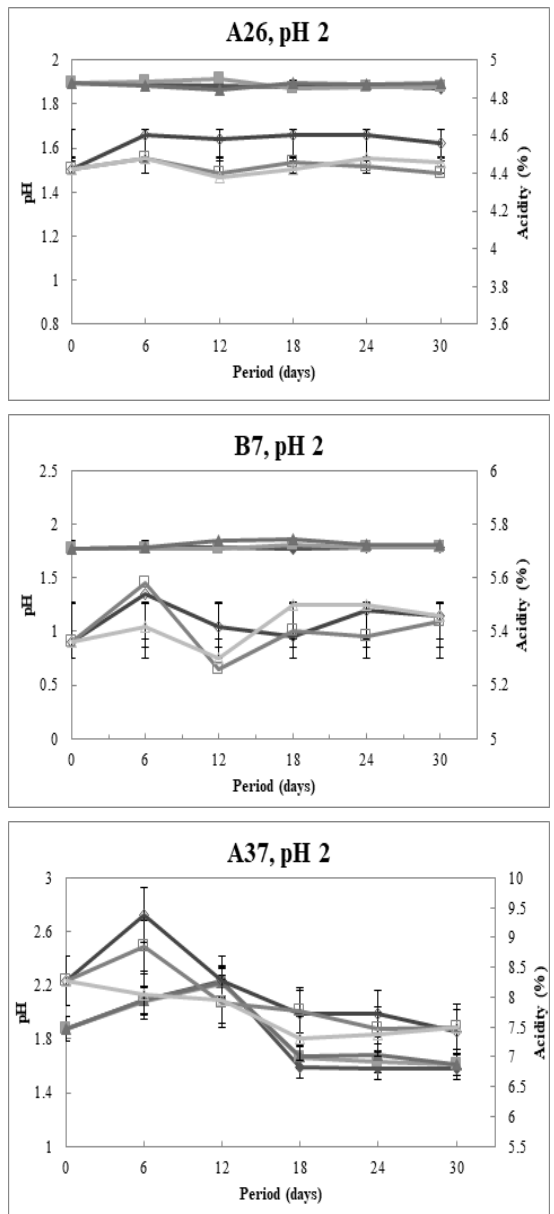
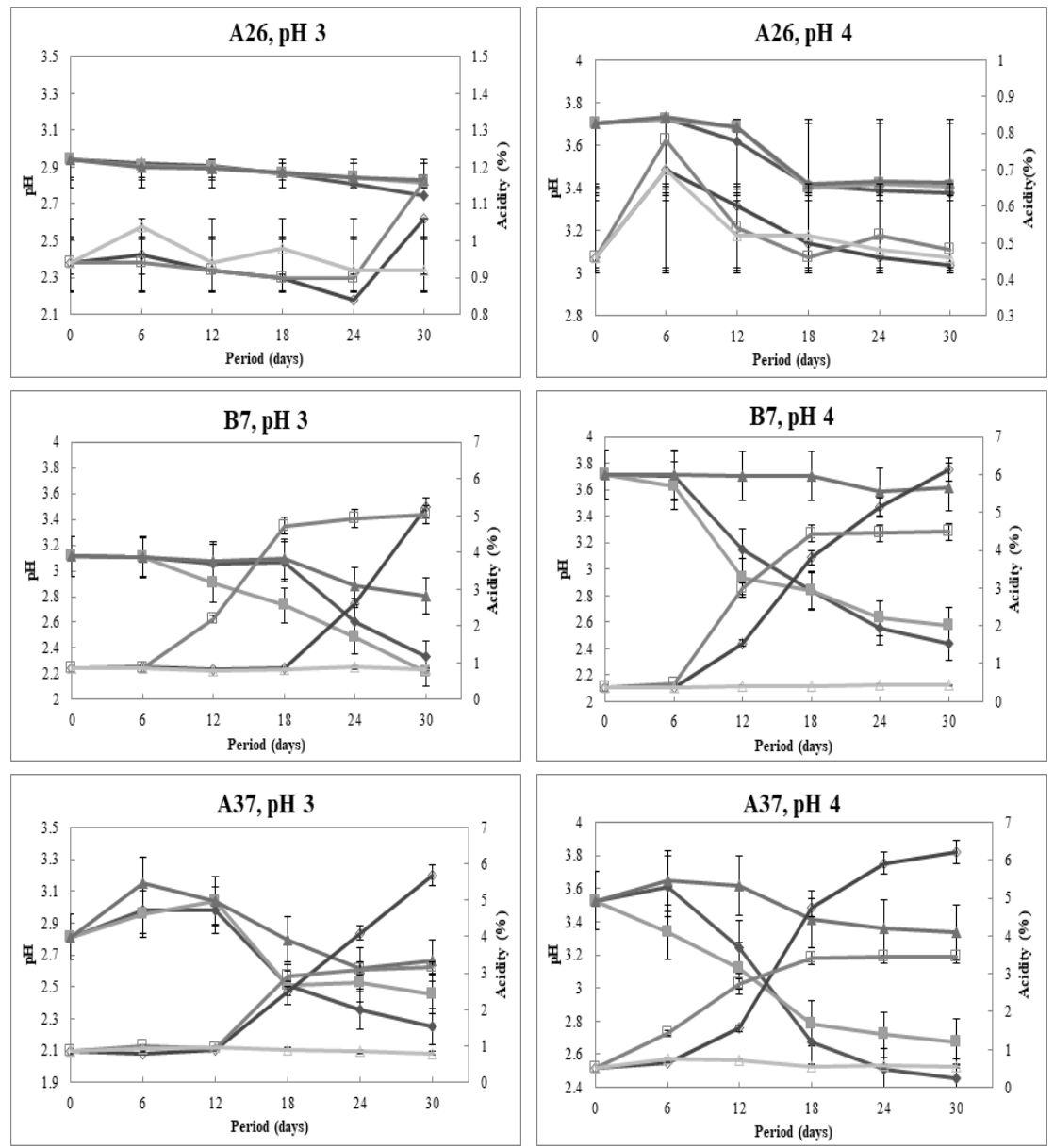

Fig. 2. Changes in $\mathrm{pH}$ and acidity during farm-made type Kujippong vinegar.

, $\mathrm{pH}, 20^{\circ} \mathrm{C} ; \mathrm{O}$, acidity, $20^{\circ} \mathrm{C} ; \boldsymbol{\square}, \mathrm{pH}, 30^{\circ} \mathrm{C} ; \square$, acidity, $30^{\circ} \mathrm{C} ; \boldsymbol{\Delta}, \mathrm{pH}, 35^{\circ} \mathrm{C} ; \triangle$, acidity, $35^{\circ} \mathrm{C}$. Data are presented as the mean for 3 independent experiments. Error bars indicate $\mathrm{SD}(\mathrm{p}<0.05)$.

서는 온도에 따른 $\mathrm{pH}$ 변화가 거의 나타나지 않았다. 초기 $\mathrm{pH} 3$ 에서는 $20^{\circ} \mathrm{C}$ 에서 $\mathrm{A} 37$ 초산균의 산도는 발효 12 일 이후 꾸준히 상승하여 발효종료 시점인 30 일에는 산도 $5.5 \%$ 를 나타내었고, B7 초산균은 발효 18 일 이후부터 상승하여 30 일의 산도가 $5.2 \%$ 를 나타내었다.

$\operatorname{Kim}$ 등(21) 보고한 보리식초에서 초기 $\mathrm{pH}$ 를 낮게 설정할 수록 유도기가 길어져 발효가 제대로 일어나지 않는다고 보고하였다. 이러한 결과는 초기 산도를 $\mathrm{pH} 2$ 로 조절한 모든 조건에서 발효가 진행되지 않아 본 연구 결과와 유사 하였다. 따라서 본 연구에서 초기 $\mathrm{pH} 4,20^{\circ} \mathrm{C}$ 가 꾸지뽕 발효 식초의 최적 발효조건으로 설정하였다.

\section{정치발효로 제조한 꾸지뽕 발효식초의 색도의 변화}

3종류 초산균으로 제조한 꾸지뽕 식초의 발효기간에 따 른 색도 변화를 Table 1-3에 나타내었다. 초산균 종류와 발효기간에 따라 L(lightness) 값이 낮아지고 $\mathrm{a}(\mathrm{red})$ 와 $\mathrm{b}$ (yellow) 값이 증가하는 경향을 나타내었다. 산 생성능이 우수한 $A$ pasteurianus $\mathrm{A} 37$ 과 $\mathrm{B} 7$ 초산균은 $\mathrm{pH} 4,20^{\circ} \mathrm{C}$ 조건
에서 L(lightness) 값이 각각 91.09 와 91.46에서 87.58과 83.02로 발효가 진행될수록 명도(L)가 낮아졌다. 이와 반대 로 $A$ pasteurianus $\mathrm{A} 37$ 초산균의 a(red) 값은 발효 전 -1.64에 서 발효 30일 종료 시점에 -0.96으로, b(yellow) 값이 11.10에 서 16.09 로 증가하였고 $\mathrm{B} 7$ 초산균은 $\mathrm{a}(\mathrm{red})$ 값이 발효 전 -1.69 에서 발효 종료 시 -0.54 로, $\mathrm{b}$ (yellow) 값이 14.50 에서 20.16 으로 증가하였다. A26 초산균은 발효 전의 L(lightness) 값이 $93 \pm 1$, 발효 종료 시 $92 \pm 1$ 로 측정되었으며, $\mathrm{a}(\mathrm{red})$ 와 b(yellow) 값 모두 큰 변화를 보이지 않았는데 이는 초산발효가 제대로 되지 않은 영향으로 보인다. Sung 등 (22)의 연구한 사과식초와 감식초 제조 시 발효가 진행됨에 따라 $\mathrm{a}(\mathrm{red})$ 값이 점차 감소되며 $\mathrm{b}(\mathrm{yellow})$ 값이 증가한다는 보고와도 유사하였다. 또한 Jang 등(23), Jo 등(24), Kim 등 (25)이 다양한 제조법으로 인한 색도 변화를 보고한 선행 연구에서도 제조된 식초 색상은 원료 및 발효 방법에 따른 차이에 기인한다고 알려져 있다. 
Table 1. Changes in color value of Kujippong vinegar using Acetobacter pasteurianus A26 during fermentation period

\begin{tabular}{|c|c|c|c|c|c|c|c|c|c|c|}
\hline \multirow{3}{*}{$\begin{array}{l}\text { Color } \\
\text { value }^{2)}\end{array}$} & \multirow{3}{*}{$\begin{array}{l}\text { Period } \\
\text { (days) }\end{array}$} & \multicolumn{9}{|c|}{ Treatment ${ }^{1)}$} \\
\hline & & \multicolumn{3}{|c|}{$\mathrm{pH} 2$} & \multicolumn{3}{|c|}{$\mathrm{pH} 3$} & \multicolumn{3}{|c|}{$\mathrm{pH} 4$} \\
\hline & & $20^{\circ} \mathrm{C}$ & $30^{\circ} \mathrm{C}$ & $35^{\circ} \mathrm{C}$ & $20^{\circ} \mathrm{C}$ & $30^{\circ} \mathrm{C}$ & $35^{\circ} \mathrm{C}$ & $20^{\circ} \mathrm{C}$ & $30^{\circ} \mathrm{C}$ & $35^{\circ} \mathrm{C}$ \\
\hline \multirow{6}{*}{$\mathrm{L}$} & 0 & $93.89 \pm 0.03^{3)}$ & $93.89 \pm 0.03$ & $93.89 \pm 0.03$ & $93.87 \pm 0.06$ & $93.87 \pm 0.06$ & $93.87 \pm 0.06$ & $93.21 \pm 0.05$ & $93.21 \pm 0.05$ & $93.21 \pm 0.05$ \\
\hline & 6 & $94.19 \pm 0.01$ & $94.19 \pm 0.02$ & $93.89 \pm 0.05$ & $93.86 \pm 0.07$ & $93.15 \pm 0.03$ & $92.43 \pm 0.03$ & $93.70 \pm 0.04$ & $93.11 \pm 0.01$ & $92.16 \pm 0.04$ \\
\hline & 12 & $93.96 \pm 0.01$ & $94.28 \pm 0.01$ & $93.73 \pm 0.07$ & $93.80 \pm 0.01$ & $92.28 \pm 0.02$ & $92.45 \pm 0.03$ & $93.78 \pm 0.03$ & $91.27 \pm 0.09$ & $92.07 \pm 0.02$ \\
\hline & 18 & $94.37 \pm 0.01$ & $93.62 \pm 0.05$ & $73.07 \pm 0.01$ & $83.77 \pm 0.01$ & $92.82 \pm 0.01$ & $92.61 \pm 0.02$ & $93.62 \pm 0.01$ & $92.37 \pm 0.07$ & $92.53 \pm 0.04$ \\
\hline & 24 & $94.22 \pm 0.02$ & $93.47 \pm 0.05$ & $92.61 \pm 0.02$ & $93.64 \pm 0.03$ & $92.85 \pm 0.03$ & $92.41 \pm 0.02$ & $93.21 \pm 0.02$ & $92.44 \pm 0.04$ & $91.96 \pm 0.05$ \\
\hline & 30 & $94.16 \pm 0.03$ & $93.38 \pm 0.01$ & $92.38 \pm 0.03$ & $93.35 \pm 0.02$ & $92.89 \pm 0.03$ & $92.30 \pm 0.01$ & $92.49 \pm 0.01$ & $92.50 \pm 0.04$ & $91.88 \pm 0.04$ \\
\hline \multirow{6}{*}{ a } & 0 & $-1.07 \pm 0.01$ & $-1.07 \pm 0.01$ & $-1.07 \pm 0.01$ & $-1.54 \pm 0.02$ & $-1.54 \pm 0.02$ & $-1.54 \pm 0.02$ & $-1.60 \pm 0.03$ & $-1.60 \pm 0.03$ & $-1.60 \pm 0.03$ \\
\hline & 6 & $-1.32 \pm 0.02$ & $-1.74 \pm 0.01$ & $-1.93 \pm 0.05$ & $-1.49 \pm 0.03$ & $-1.45 \pm 0.04$ & $-1.45 \pm 0.02$ & $-1.70 \pm 0.02$ & $-1.73 \pm 0.07$ & $-1.67 \pm 0.02$ \\
\hline & 12 & $-2.26 \pm 0.01$ & $-1.54 \pm 0.02$ & $-2.35 \pm 0.07$ & $-1.49 \pm 0.03$ & $-1.57 \pm 0.05$ & $-1.81 \pm 0.02$ & $-1.76 \pm 0.01$ & $-1.62 \pm 0.05$ & $-2.07 \pm 0.03$ \\
\hline & 18 & $-1.76 \pm 0.01$ & $-2.44 \pm 0.01$ & $-2.52 \pm 0.04$ & $-1.47 \pm 0.01$ & $-1.87 \pm 0.01$ & $-1.77 \pm 0.03$ & $-1.73 \pm 0.01$ & $-2.21 \pm 0.01$ & $-1.96 \pm 0.01$ \\
\hline & 24 & $-1.93 \pm 0.05$ & $-2.28 \pm 0.03$ & $-2.27 \pm 0.04$ & $-1.46 \pm 0.01$ & $-1.86 \pm 0.01$ & $-1.75 \pm 0.01$ & $-1.64 \pm 0.02$ & $-2.21 \pm 0.03$ & $-1.85 \pm 0.01$ \\
\hline & 30 & $-1.99 \pm 0.05$ & $-2.24 \pm 0.01$ & $-2.24 \pm 0.01$ & $-1.45 \pm 0.04$ & $-1.80 \pm 0.01$ & $-1.70 \pm 0.01$ & $-1.54 \pm 0.01$ & $-2.08 \pm 0.04$ & $-1.78 \pm 0.03$ \\
\hline \multirow{6}{*}{$\mathrm{b}$} & 0 & $8.58 \pm 0.05$ & $8.58 \pm 0.05$ & $8.58 \pm 0.05$ & $9.17 \pm 0.07$ & $9.17 \pm 0.07$ & $9.17 \pm 0.07$ & $9.83 \pm 0.01$ & $9.83 \pm 0.01$ & $9.83 \pm 0.01$ \\
\hline & 6 & $8.10 \pm 0.01$ & $9.64 \pm 0.04$ & $10.81 \pm 0.01$ & $9.11 \pm 0.05$ & $10.78 \pm 0.05$ & $12.59 \pm 0.06$ & $9.67 \pm 0.02$ & $11.62 \pm 0.03$ & $13.82 \pm 0.01$ \\
\hline & 12 & $12.10 \pm 0.05$ & $8.65 \pm 0.03$ & $12.66 \pm 0.02$ & $9.45 \pm 0.02$ & $14.09 \pm 0.06$ & $13.65 \pm 0.01$ & $10.21 \pm 0.03$ & $17.28 \pm 0.02$ & $15.28 \pm 0.01$ \\
\hline & 18 & $9.39 \pm 0.05$ & $14.07 \pm 0.02$ & $16.28 \pm 0.01$ & $10.11 \pm 0.03$ & $13.30 \pm 0.07$ & $13.68 \pm 0.01$ & $11.33 \pm 0.03$ & $15.92 \pm 0.03$ & $14.78 \pm 0.04$ \\
\hline & 24 & $10.58 \pm 0.04$ & $14.44 \pm 0.03$ & $17.37 \pm 0.01$ & $10.87 \pm 0.03$ & $13.42 \pm 0.03$ & $14.54 \pm 0.01$ & $12.78 \pm 0.07$ & $16.06 \pm 0.01$ & $15.85 \pm 0.06$ \\
\hline & 30 & $10.94 \pm 0.03$ & $14.70 \pm 0.01$ & $18.02 \pm 0.02$ & $11.89 \pm 0.01$ & $13.19 \pm 0.01$ & $14.81 \pm 0.02$ & $14.76 \pm 0.08$ & $15.54 \pm 0.06$ & $16.20 \pm 0.05$ \\
\hline
\end{tabular}

${ }^{1)} \mathrm{pH}$, initial acidity; ${ }^{\circ} \mathrm{C}$, fermentation temperature.

${ }^{2)} \mathrm{L}$, lightness; a, red; b, yellow.

${ }^{3}$ Data values were expressed as mean \pm SD of triplicate determinations.

Table 2. Changes in color value of Kujippong vinegar using Acetobacter pasteurianus A37 during fermentation period

\begin{tabular}{|c|c|c|c|c|c|c|c|c|c|c|}
\hline \multirow{3}{*}{$\begin{array}{l}\text { Color } \\
\text { value }\end{array}$} & \multirow{3}{*}{$\begin{array}{l}\text { Period } \\
\text { (days) }\end{array}$} & \multicolumn{9}{|c|}{ Treatment ${ }^{1)}$} \\
\hline & & \multicolumn{3}{|c|}{$\mathrm{pH} 2$} & \multicolumn{3}{|c|}{$\mathrm{pH} 3$} & \multicolumn{3}{|c|}{$\mathrm{pH} 4$} \\
\hline & & $20^{\circ} \mathrm{C}$ & $30^{\circ} \mathrm{C}$ & $35^{\circ} \mathrm{C}$ & $20^{\circ} \mathrm{C}$ & $30^{\circ} \mathrm{C}$ & $35^{\circ} \mathrm{C}$ & $20^{\circ} \mathrm{C}$ & $30^{\circ} \mathrm{C}$ & $35^{\circ} \mathrm{C}$ \\
\hline \multirow{6}{*}{$\mathrm{L}$} & 0 & $92.07 \pm 0.02^{3)}$ & $92.07 \pm 0.02$ & $92.07 \pm 0.02$ & $92.09 \pm 0.01$ & $92.09 \pm 0.01$ & $92.09 \pm 0.01$ & $91.09 \pm 0.01$ & $91.09 \pm 0.01$ & $91.09 \pm 0.01$ \\
\hline & 6 & $93.33 \pm 0.05$ & $93.03 \pm 0.01$ & $92.89 \pm 0.01$ & $92.69 \pm 0.01$ & $91.81 \pm 0.01$ & $91.59 \pm 0.02$ & $92.47 \pm 0.04$ & $82.44 \pm 0.02$ & $90.89 \pm 0.02$ \\
\hline & 12 & $93.59 \pm 0.01$ & $93.23 \pm 0.01$ & $93.04 \pm 0.02$ & $92.29 \pm 0.01$ & $91.77 \pm 0.03$ & $91.44 \pm 0.03$ & $91.80 \pm 0.03$ & $91.61 \pm 0.01$ & $90.72 \pm 0.03$ \\
\hline & 18 & $93.94 \pm 0.04$ & $93.23 \pm 0.05$ & $92.98 \pm 0.01$ & $86.12 \pm 0.04$ & $91.29 \pm 0.07$ & $91.62 \pm 0.03$ & $88.37 \pm 0.01$ & $91.78 \pm 0.08$ & $91.08 \pm 0.05$ \\
\hline & 24 & $93.97 \pm 0.04$ & $93.54 \pm 0.04$ & $92.93 \pm 0.01$ & $82.33 \pm 0.03$ & $91.34 \pm 0.01$ & $91.65 \pm 0.04$ & $88.97 \pm 0.03$ & $87.56 \pm 0.03$ & $90.83 \pm 0.01$ \\
\hline & 30 & $93.77 \pm 0.01$ & $93.57 \pm 0.01$ & $93.02 \pm 0.04$ & $81.59 \pm 0.02$ & $90.97 \pm 0.05$ & $92.00 \pm 0.02$ & $87.58 \pm 0.01$ & $90.21 \pm 0.03$ & $90.38 \pm 0.04$ \\
\hline \multirow{6}{*}{$\mathrm{a}$} & 0 & $-0.73 \pm 0.03$ & $-0.73 \pm 0.03$ & $-0.73 \pm 0.03$ & $-1.55 \pm 0.02$ & $-1.55 \pm 0.02$ & $-1.55 \pm 0.02$ & $-1.64 \pm 0.03$ & $-1.64 \pm 0.03$ & $-1.64 \pm 0.03$ \\
\hline & 6 & $-0.81 \pm 0.04$ & $-0.93 \pm 0.01$ & $-1.01 \pm 0.03$ & $-1.55 \pm 0.03$ & $-1.53 \pm 0.05$ & $-1.53 \pm 0.04$ & $-1.76 \pm 0.07$ & $-1.98 \pm 0.05$ & $-1.70 \pm 0.06$ \\
\hline & 12 & $-0.89 \pm 0.03$ & $-1.01 \pm 0.03$ & $-1.06 \pm 0.03$ & $-1.54 \pm 0.03$ & $-1.66 \pm 0.03$ & $-1.80 \pm 0.03$ & $-1.76 \pm 0.05$ & $-1.91 \pm 0.05$ & $-2.28 \pm 0.03$ \\
\hline & 18 & $-0.98 \pm 0.01$ & $-1.14 \pm 0.01$ & $-1.18 \pm 0.03$ & $-0.58 \pm 0.01$ & $-1.64 \pm 0.03$ & $-1.77 \pm 0.01$ & $-1.21 \pm 0.03$ & $-1.93 \pm 0.03$ & $-2.14 \pm 0.01$ \\
\hline & 24 & $-1.03 \pm 0.01$ & $-1.22 \pm 0.03$ & $-1.25 \pm 0.01$ & $0.07 \pm 0.03$ & $-1.61 \pm 0.01$ & $-1.77 \pm 0.03$ & $-1.34 \pm 0.03$ & $-1.18 \pm 0.04$ & $-2.08 \pm 0.03$ \\
\hline & 30 & $-1.01 \pm 0.07$ & $-1.27 \pm 0.04$ & $-1.32 \pm 0.08$ & $0.28 \pm 0.01$ & $-1.57 \pm 0.03$ & $-1.81 \pm 0.08$ & $-0.98 \pm 0.03$ & $-1.71 \pm 0.01$ & $-1.93 \pm 0.01$ \\
\hline \multirow{6}{*}{$\mathrm{b}$} & 0 & $8.30 \pm 0.05$ & $8.30 \pm 0.05$ & $8.30 \pm 0.05$ & $10.66 \pm 0.03$ & $10.66 \pm 0.03$ & $10.66 \pm 0.03$ & $11.10 \pm 0.01$ & $11.10 \pm 0.01$ & $11.10 \pm 0.01$ \\
\hline & 6 & $6.62 \pm 0.01$ & $7.80 \pm 0.06$ & $8.49 \pm 0.05$ & $10.39 \pm 0.01$ & $11.83 \pm 0.02$ & $12.97 \pm 0.04$ & $11.21 \pm 0.04$ & $13.08 \pm 0.04$ & $16.54 \pm 0.02$ \\
\hline & 12 & $6.79 \pm 0.03$ & $8.26 \pm 0.01$ & $9.09 \pm 0.07$ & $10.95 \pm 0.01$ & $13.18 \pm 0.01$ & $15.31 \pm 0.01$ & $12.12 \pm 0.01$ & $15.35 \pm 0.01$ & $19.32 \pm 0.01$ \\
\hline & 18 & $6.95 \pm 0.04$ & $8.30 \pm 0.01$ & $9.62 \pm 0.04$ & $14.71 \pm 0.06$ & $14.57 \pm 0.03$ & $14.71 \pm 0.01$ & $14.64 \pm 0.02$ & $16.38 \pm 0.01$ & $18.52 \pm 0.03$ \\
\hline & 24 & $7.14 \pm 0.01$ & $8.60 \pm 0.03$ & $10.11 \pm 0.03$ & $16.76 \pm 0.02$ & $14.98 \pm 0.02$ & $15.29 \pm 0.03$ & $14.65 \pm 0.03$ & $19.21 \pm 0.05$ & $19.13 \pm 0.01$ \\
\hline & 30 & $7.20 \pm 0.01$ & $8.77 \pm 0.08$ & $10.49 \pm 0.04$ & $17.43 \pm 0.08$ & $16.67 \pm 0.06$ & $15.56 \pm 0.03$ & $16.09 \pm 0.01$ & $19.92 \pm 0.02$ & $19.34 \pm 0.05$ \\
\hline
\end{tabular}

${ }^{1)} \mathrm{pH}$, initial acidity; ${ }^{\circ} \mathrm{C}$, fermentation temperature.

${ }^{2} \mathrm{~L}$, lightness; $\mathrm{a}$, red; $b$, yellow.

${ }^{33}$ Data values were expressed as mean $\pm \mathrm{SD}$ of triplicate determinations. 
Table 3. Changes in color value of Kujippong vinegar using Acetobacter pasteurianus B7 during fermentation period

\begin{tabular}{|c|c|c|c|c|c|c|c|c|c|c|}
\hline \multirow{3}{*}{$\begin{array}{l}\text { Color } \\
\text { value }^{2}\end{array}$} & \multirow{3}{*}{$\begin{array}{l}\text { Period } \\
\text { (days) }\end{array}$} & \multicolumn{9}{|c|}{ Treatment ${ }^{1)}$} \\
\hline & & \multicolumn{3}{|c|}{$\mathrm{pH} 2$} & \multicolumn{3}{|c|}{$\mathrm{pH} 3$} & \multicolumn{3}{|c|}{$\mathrm{pH} 4$} \\
\hline & & $20^{\circ} \mathrm{C}$ & $30^{\circ} \mathrm{C}$ & $35^{\circ} \mathrm{C}$ & $20^{\circ} \mathrm{C}$ & $30^{\circ} \mathrm{C}$ & $35^{\circ} \mathrm{C}$ & $20^{\circ} \mathrm{C}$ & $30^{\circ} \mathrm{C}$ & $35^{\circ} \mathrm{C}$ \\
\hline \multirow{6}{*}{$\mathrm{L}$} & 0 & $90.16 \pm 0.01^{3)}$ & $90.16 \pm 0.01$ & $90.16 \pm 0.01$ & $90.28 \pm 0.01$ & $90.28 \pm 0.01$ & $90.28 \pm 0.01$ & $91.46 \pm 0.03$ & $91.46 \pm 0.03$ & $91.46 \pm 0.03$ \\
\hline & 6 & $92.35 \pm 0.03$ & $92.60 \pm 0.07$ & $92.61 \pm 0.02$ & $92.70 \pm 0.01$ & $90.81 \pm 0.06$ & $88.87 \pm 0.02$ & $89.74 \pm 0.05$ & $90.15 \pm 0.01$ & $90.77 \pm 0.09$ \\
\hline & 12 & $93.49 \pm 0.03$ & $93.47 \pm 0.05$ & $93.19 \pm 0.06$ & $92.65 \pm 0.01$ & $68.38 \pm 0.06$ & $86.04 \pm 0.02$ & $83.77 \pm 0.01$ & $66.78 \pm 0.03$ & $85.18 \pm 0.02$ \\
\hline & 18 & $94.08 \pm 0.08$ & $94.00 \pm 0.01$ & $93.45 \pm 0.05$ & $91.83 \pm 0.03$ & $68.16 \pm 0.03$ & $87.41 \pm 0.05$ & $72.89 \pm 0.03$ & $75.52 \pm 0.06$ & $86.52 \pm 0.01$ \\
\hline & 24 & $94.34 \pm 0.03$ & $94.21 \pm 0.03$ & $93.56 \pm 0.06$ & $67.88 \pm 0.01$ & $75.30 \pm 0.03$ & $88.30 \pm 0.01$ & $82.91 \pm 0.01$ & $81.51 \pm 0.01$ & $85.66 \pm 0.05$ \\
\hline & 30 & $94.61 \pm 0.01$ & $94.54 \pm 0.04$ & $93.98 \pm 0.03$ & $65.34 \pm 0.03$ & $78.25 \pm 0.01$ & $88.98 \pm 0.05$ & $83.02 \pm 0.02$ & $85.30 \pm 0.03$ & $86.72 \pm 0.03$ \\
\hline \multirow{6}{*}{$\mathrm{a}$} & 0 & $-0.78 \pm 0.03$ & $-0.78 \pm 0.03$ & $-0.78 \pm 0.03$ & $-1.34 \pm 0.02$ & $-1.34 \pm 0.02$ & $-1.34 \pm 0.02$ & $-1.69 \pm 0.01$ & $-1.69 \pm 0.01$ & $-1.69 \pm 0.01$ \\
\hline & 6 & $-0.93 \pm 0.05$ & $-1.25 \pm 0.06$ & $-1.41 \pm 0.04$ & $-1.71 \pm 0.02$ & $-1.65 \pm 0.08$ & $-1.20 \pm 0.07$ & $-1.33 \pm 0.02$ & $-1.81 \pm 0.03$ & $-2.08 \pm 0.02$ \\
\hline & 12 & $-1.19 \pm 0.01$ & $-1.76 \pm 0.05$ & $-1.80 \pm 0.03$ & $-1.74 \pm 0.04$ & $2.43 \pm 0.04$ & $-0.93 \pm 0.10$ & $-0.59 \pm 0.01$ & $2.53 \pm 0.05$ & $-0.29 \pm 0.08$ \\
\hline & 18 & $-1.31 \pm 0.01$ & $-1.73 \pm 0.02$ & $-1.75 \pm 0.03$ & $-1.70 \pm 0.07$ & $2.63 \pm 0.05$ & $-2.08 \pm 0.03$ & $1.41 \pm 0.01$ & $1.07 \pm 0.03$ & $-1.78 \pm 0.01$ \\
\hline & 24 & $-1.46 \pm 0.01$ & $-1.76 \pm 0.07$ & $-1.83 \pm 0.03$ & $2.54 \pm 0.03$ & $1.60 \pm 0.03$ & $-1.95 \pm 0.08$ & $-0.42 \pm 0.02$ & $-0.10 \pm 0.03$ & $-1.27 \pm 0.06$ \\
\hline & 30 & $-1.68 \pm 0.02$ & $-1.75 \pm 0.01$ & $-1.86 \pm 0.06$ & $2.78 \pm 0.02$ & $1.89 \pm 0.04$ & $-1.88 \pm 0.01$ & $-0.54 \pm 0.01$ & $-0.36 \pm 0.01$ & $-1.36 \pm 0.03$ \\
\hline \multirow{6}{*}{$\mathrm{b}$} & 0 & $9.32 \pm 0.02$ & $9.32 \pm 0.02$ & $9.32 \pm 0.02$ & $13.85 \pm 0.01$ & $13.85 \pm 0.01$ & $13.85 \pm 0.01$ & $14.50 \pm 0.05$ & $14.50 \pm 0.05$ & $14.50 \pm 0.05$ \\
\hline & 6 & $9.51 \pm 0.09$ & $10.58 \pm 0.06$ & $11.13 \pm 0.03$ & $13.02 \pm 0.01$ & $17.61 \pm 0.10$ & $24.07 \pm 0.05$ & $14.62 \pm 0.02$ & $17.31 \pm 0.06$ & $20.81 \pm 0.02$ \\
\hline & 12 & $8.86 \pm 0.01$ & $11.65 \pm 0.04$ & $12.66 \pm 0.03$ & $13.03 \pm 0.01$ & $27.22 \pm 0.03$ & $38.47 \pm 0.03$ & $18.12 \pm 0.01$ & $27.93 \pm 0.03$ & $37.53 \pm 0.01$ \\
\hline & 18 & $8.73 \pm 0.01$ & $11.35 \pm 0.05$ & $12.97 \pm 0.01$ & $15.45 \pm 0.05$ & $29.07 \pm 0.04$ & $33.74 \pm 0.05$ & $22.26 \pm 0.01$ & $28.42 \pm 0.05$ & $33.91 \pm 0.02$ \\
\hline & 24 & $9.17 \pm 0.03$ & $11.57 \pm 0.03$ & $13.68 \pm 0.01$ & $23.43 \pm 0.04$ & $30.65 \pm 0.01$ & $33.01 \pm 0.04$ & $20.76 \pm 0.02$ & $28.24 \pm 0.02$ & $33.31 \pm 0.01$ \\
\hline & 30 & $9.59 \pm 0.02$ & $11.88 \pm 0.04$ & $14.02 \pm 0.06$ & $24.21 \pm 0.02$ & $31.26 \pm 0.01$ & $32.65 \pm 0.07$ & $20.16 \pm 0.01$ & $28.03 \pm 0.03$ & $33.10 \pm 0.04$ \\
\hline
\end{tabular}

${ }^{1)} \mathrm{pH}$, initial acidity; ${ }^{\circ} \mathrm{C}$, fermentation temperature.

${ }^{2)} \mathrm{L}$, lightness; a, red; b, yellow.

${ }^{3}$ Data values were expressed as mean \pm SD of triplicate determinations.

Table 4. The organic acid content according to fermentation period of Kujippong vinegar by optimum conditions

(Unit : $\mathrm{mg} / \mathrm{mL}$ )

\begin{tabular}{|c|c|c|c|c|c|c|c|c|}
\hline \multirow{2}{*}{$\begin{array}{l}\text { Treat- } \\
\text { ment }^{1)}\end{array}$} & \multirow{2}{*}{ Strain } & \multirow{2}{*}{$\begin{array}{l}\text { Period } \\
\text { (days) }\end{array}$} & \multicolumn{6}{|c|}{ Organic acid } \\
\hline & & & Acetic acid & Lactic acid & Succinic acid & Malic acid & Citric acid & Total \\
\hline \multirow{18}{*}{$\mathrm{pH} 4,20^{\circ} \mathrm{C}$} & \multirow{6}{*}{$\mathrm{A} 26$} & 0 & $2.37 \pm 0.21^{22)}$ & $0.87 \pm 0.02^{\mathrm{ab}}$ & $0.04 \pm 0.01^{\mathrm{a}}$ & ND3) & $4.41 \pm 0.03^{c}$ & $7.69 \pm 0.25$ \\
\hline & & 6 & $2.44 \pm 0.19^{\mathrm{a}}$ & $0.83 \pm 0.02^{\mathrm{bc}}$ & $0.04 \pm 0.01^{\mathrm{a}}$ & ND & $4.44 \pm 0.03^{\mathrm{c}}$ & $7.76 \pm 0.25$ \\
\hline & & 12 & $2.48 \pm 0.29^{\mathrm{a}}$ & $0.88 \pm 0.01^{\mathrm{a}}$ & $0.04 \pm 0.01^{\mathrm{a}}$ & ND & $4.54 \pm 0.06^{\mathrm{b}}$ & $7.93 \pm 0.36$ \\
\hline & & 18 & $2.52 \pm 0.19^{\mathrm{a}}$ & $0.86 \pm 0.03^{\mathrm{ab}}$ & $0.04 \pm 0.01^{\mathrm{a}}$ & ND & $4.54 \pm 0.04^{b}$ & $7.97 \pm 0.26$ \\
\hline & & 24 & $2.69 \pm 0.08^{\mathrm{a}}$ & $0.87 \pm 0.02^{\mathrm{a}}$ & $0.04 \pm 0.01^{\mathrm{a}}$ & ND & $4.59 \pm 0.04^{\mathrm{ab}}$ & $8.19 \pm 0.13$ \\
\hline & & 30 & $2.63 \pm 0.23^{\mathrm{a}}$ & $0.81 \pm 0.02^{c}$ & $0.05 \pm 0.01^{\mathrm{a}}$ & ND & $4.64 \pm 0.04^{\mathrm{a}}$ & $8.12 \pm 0.29$ \\
\hline & \multirow{6}{*}{ A37 } & 0 & $2.50 \pm 0.08^{\mathrm{d}}$ & $0.94 \pm 0.03^{b}$ & $0.04 \pm 0.01^{\mathrm{a}}$ & ND & $0.17 \pm 0.08^{\mathrm{a}}$ & $3.66 \pm 0.19$ \\
\hline & & 6 & $2.51 \pm 0.04^{\mathrm{d}}$ & $0.87 \pm 0.06^{\mathrm{b}}$ & $0.04 \pm 0.01^{\mathrm{a}}$ & ND & $0.17 \pm 0.05^{\mathrm{a}}$ & $3.59 \pm 0.15$ \\
\hline & & 12 & $9.38 \pm 0.05^{c}$ & $1.10 \pm 0.07^{\mathrm{a}}$ & $0.04 \pm 0.0 .1^{\mathrm{a}}$ & ND & $0.17 \pm 0.02^{\mathrm{a}}$ & $10.69 \pm 0.15$ \\
\hline & & 18 & $28.47 \pm 0.73^{b}$ & $1.11 \pm 0.02^{\mathrm{a}}$ & $0.04 \pm 0.01^{\mathrm{a}}$ & ND & $0.20 \pm 0.01^{\mathrm{a}}$ & $29.82 \pm 0.76$ \\
\hline & & 24 & $35.95 \pm 2.90^{\mathrm{a}}$ & $1.09 \pm 0.05^{\mathrm{a}}$ & $0.04 \pm 0.01^{\mathrm{a}}$ & ND & $0.20 \pm 0.01^{\mathrm{a}}$ & $37.28 \pm 2.97$ \\
\hline & & 30 & $37.66 \pm 0.65^{\mathrm{a}}$ & $1.03 \pm 0.05^{\mathrm{a}}$ & $0.04 \pm 0.01^{\mathrm{a}}$ & ND & $0.20 \pm 0.03^{\mathrm{a}}$ & $38.93 \pm 0.73$ \\
\hline & \multirow{6}{*}{ B7 } & 0 & $2.36 \pm 0.19^{\mathrm{e}}$ & $0.85 \pm 0.04^{\mathrm{d}}$ & $0.04 \pm 0.01^{\mathrm{a}}$ & ND & $0.24 \pm 0.03^{\mathrm{a}}$ & $3.49 \pm 0.26$ \\
\hline & & 6 & $2.41 \pm 0.17^{\mathrm{e}}$ & $0.83 \pm 0.02^{d}$ & $0.04 \pm 0.01^{\mathrm{a}}$ & ND & $0.26 \pm 0.02^{\mathrm{a}}$ & $3.54 \pm 0.21$ \\
\hline & & 12 & $9.78 \pm 0.09^{d}$ & $1.54 \pm 0.10^{c}$ & $0.04 \pm 0.01^{\mathrm{a}}$ & ND & $0.25 \pm 0.03^{\mathrm{a}}$ & $11.61 \pm 0.23$ \\
\hline & & 18 & $23.73 \pm 2.00^{c}$ & $1.57 \pm 0.02^{\mathrm{bc}}$ & $0.04 \pm 0.01^{\mathrm{a}}$ & ND & $0.26 \pm 0.01^{\mathrm{a}}$ & $25.60 \pm 2.03$ \\
\hline & & 24 & $32.68 \pm 2.17^{b}$ & $1.68 \pm 0.12^{\mathrm{b}}$ & $0.03 \pm 0.01^{\mathrm{a}}$ & ND & $0.27 \pm 0.01^{\mathrm{a}}$ & $34.66 \pm 2.31$ \\
\hline & & 30 & $39.27 \pm 0.87^{\mathrm{a}}$ & $2.03 \pm 0.05^{\mathrm{a}}$ & $0.03 \pm 0.01^{\mathrm{a}}$ & ND & $0.27 \pm 0.02^{\mathrm{a}}$ & $41.60 \pm 0.95$ \\
\hline
\end{tabular}

${ }^{1)} \mathrm{pH} 4$, initial acidity; $20^{\circ} \mathrm{C}$, fermentation temperature.

${ }^{2)}$ Means \pm SD. Different letters in the same row are significantly different $(\mathrm{p}<0.05)$ by duncan's multiple range test.

${ }^{3)} \mathrm{ND}$, not detected. 


\section{꾸지뽕 발효식초의 유기산 함량 변화}

과일식초의 산미와 지미를 형성하는 초산(acetic acid)을 비롯한 유기산의 구성은 TCA 회로를 활성화하여 젖산분해 촉진 등의 기능성을 가진다고 보고되어 있다(26). 초기 산도 $(\mathrm{pH} 2,3,4)$ 와 발효온도 $\left(20,30,35^{\circ} \mathrm{C}\right)$ 를 달리하여 제조한 꾸지뽕 발효식초의 이화학적 분석 결과를 바탕으로 발효능 이 뛰어난 최적조건 $\left(\mathrm{pH} 4\right.$ 와 $\left.20^{\circ} \mathrm{C}\right)$ 에서 초산균 종류별로 꾸지뽕 발효식초를 제조한 후, 이들의 유기산 함량 변화를 분석한 결과, 발효기간이 경과함에 따라 유기산 함량이 경 시적으로 증가하는 것을 확인할 수 있었다(Table 4).

초산균 A37과 B7로 제조한 꾸지뽕 발효식초의 유기산
함량은 발효 초기인 0 일과 비교한 결과, $\mathrm{A} 37$ 은 38.67 $\mathrm{mg} / \mathrm{mL}, \mathrm{B} 7$ 은 $41.66 \mathrm{mg} / \mathrm{mL}$ 로 약 10 배 정도 증가하였다. $\mathrm{A} 37$ 과 B7 초산균으로 빚은 꾸지뽕 식초의 유기산 중에서도 acetic acid가 각각 $37.34 \mathrm{mg} / \mathrm{mL}, 39.34 \mathrm{mg} / \mathrm{mL}$ 로 가장 많은 함량을 나타낸 주요 유기산이었다. 이러한 결과는 Jeong 등(27)의 사과식초에서 $46.02 \mathrm{mg} / \mathrm{mL}, \mathrm{Kim}$ 등(28)의 매실식 초에서 $32.27 \mathrm{mg} / \mathrm{mL}$ 그리고 $\mathrm{Ko}(29)$ 의 막걸리식초에 꾸지 뽕 열매를 첨가하여 제조한 식초에서 $39.02 \mathrm{mg} / \mathrm{mL}$ 로 검출 된 선행 연구 결과와 초산 함량 등이 비슷한 것으로 보아 꾸지뽕 열매가 식초제조의 원료로서 가능성을 짐작할 수 있었다.

Table 5. The free amino acid content according to fermentation period of Kujïpong vinegar by optimum conditions

(Unit : $\mathrm{mg} / \mathrm{mL}$ )

\begin{tabular}{|c|c|c|c|c|c|c|c|c|c|c|c|c|c|c|c|c|c|c|}
\hline \multirow{3}{*}{ Amino acid } & \multicolumn{18}{|c|}{$\mathrm{pH} 4,20^{\circ} \mathrm{C}$} \\
\hline & \multicolumn{6}{|c|}{ A26 } & \multicolumn{6}{|c|}{ A37 } & \multicolumn{6}{|c|}{ B7 } \\
\hline & 0 & 6 & 12 & 18 & 24 & 30 & 0 & 6 & 12 & 18 & 24 & 30 & 0 & 6 & 12 & 18 & 24 & 30 \\
\hline Phosphoserine & 0.011 & 0.012 & 0.018 & 0.013 & 0.015 & 0.015 & 0.014 & 0.014 & 0.015 & 0.014 & 0.012 & 0.012 & 0.024 & 0.021 & 0.020 & 0.027 & 0.018 & 0.027 \\
\hline Taurine & 0.001 & 0.001 & 0.002 & 0.001 & 0.002 & 0.002 & 0.001 & 0.001 & 0.001 & 0.001 & 0.002 & 0.002 & 0.002 & 0.003 & 0.002 & 0.002 & 0.001 & 0.002 \\
\hline Aspartic acid & 0.003 & 0.002 & 0.003 & 0.003 & 0.005 & 0.005 & 0.003 & 0.001 & 0.001 & $\mathrm{ND}$ & $\mathrm{ND}$ & ND & $\mathrm{ND}$ & $\mathrm{ND}$ & $\mathrm{ND}$ & $\mathrm{ND}$ & $\mathrm{ND}$ & ND \\
\hline Threonine & 0.002 & 0.001 & 0.002 & 0.002 & 0.002 & 0.002 & 0.002 & 0.001 & 0.001 & $\mathrm{ND}$ & $\mathrm{ND}$ & ND & 0.007 & 0.006 & $\mathrm{ND}$ & $\mathrm{ND}$ & $\mathrm{ND}$ & $\mathrm{ND}$ \\
\hline Serine & 0.001 & 0.001 & 0.001 & 0.001 & 0.002 & 0.001 & 0.001 & 0.001 & ND & $\mathrm{ND}$ & $\mathrm{ND}$ & ND & 0.004 & 0.004 & $\mathrm{ND}$ & $\mathrm{ND}$ & $\mathrm{ND}$ & ND \\
\hline Asparagine & 0.002 & 0.001 & 0.001 & 0.001 & 0.002 & 0.001 & 0.002 & 0.002 & $\mathrm{ND}$ & $\mathrm{ND}$ & $\mathrm{ND}$ & ND & 0.002 & 0.002 & $\mathrm{ND}$ & $\mathrm{ND}$ & ND & ND \\
\hline Glutamic acid & 0.010 & 0.007 & 0.010 & 0.011 & 0.016 & 0.015 & 0.01 & 0.009 & 0.001 & ND & ND & ND & 0.021 & 0.022 & 0.019 & 0.009 & 0.004 & 0.005 \\
\hline Proline & 0.019 & 0.014 & 0.017 & 0.016 & 0.024 & 0.021 & 0.017 & 0.014 & 0.002 & 0.001 & 0.001 & 0.001 & 0.127 & 0.128 & 0.023 & $\mathrm{ND}$ & ND & $\mathrm{ND}$ \\
\hline Glycine & 0.002 & 0.002 & 0.002 & 0.002 & 0.003 & 0.002 & 0.002 & 0.002 & ND & 0.001 & 0.001 & ND & 0.005 & 0.005 & $\mathrm{ND}$ & $\mathrm{ND}$ & $\mathrm{ND}$ & ND \\
\hline Alanine & 0.010 & 0.007 & 0.009 & 0.008 & 0.012 & 0.010 & 0.010 & 0.008 & ND & 0.004 & 0.003 & ND & 0.021 & 0.022 & 0.001 & $\mathrm{ND}$ & ND & $\mathrm{ND}$ \\
\hline Valine & 0.002 & 0.002 & 0.002 & 0.002 & 0.003 & 0.002 & 0.002 & 0.002 & 0.002 & ND & $\mathrm{ND}$ & 0.001 & 0.006 & 0.007 & 0.002 & 0.001 & 0.001 & 0.001 \\
\hline Cystine & 0.006 & 0.004 & 0.004 & 0.003 & 0.004 & 0.003 & 0.007 & 0.005 & 0.005 & $\mathrm{ND}$ & $\mathrm{ND}$ & 0.004 & 0.01 & 0.01 & 0.006 & 0.008 & 0.005 & 0.007 \\
\hline Methionine & $\mathrm{ND}^{2)}$ & $\mathrm{ND}$ & $\mathrm{ND}$ & ND & ND & ND & $\mathrm{ND}$ & $\mathrm{ND}$ & ND & $\mathrm{ND}$ & $\mathrm{ND}$ & ND & ND & $\mathrm{ND}$ & $\mathrm{ND}$ & $\mathrm{ND}$ & ND & ND \\
\hline Isoleucine & 0.005 & 0.003 & 0.004 & 0.004 & 0.006 & 0.005 & 0.004 & 0.003 & 0.002 & 0.001 & 0.001 & 0.001 & 0.010 & 0.010 & 0.005 & 0.004 & 0.002 & 0.003 \\
\hline Leucine & 0.005 & 0.003 & 0.004 & 0.004 & 0.005 & 0.005 & 0.003 & 0.003 & 0.001 & $\mathrm{ND}$ & $\mathrm{ND}$ & ND & 0.011 & 0.011 & 0.004 & 0.002 & 0.001 & 0.001 \\
\hline Tyrosine & 0.003 & 0.002 & 0.002 & 0.002 & 0.003 & 0.003 & 0.002 & 0.002 & 0.002 & 0.002 & 0.002 & 0.002 & 0.005 & 0.006 & 0.003 & 0.005 & 0.003 & 0.004 \\
\hline Phenylalanine & 0.005 & 0.003 & 0.004 & 0.006 & 0.005 & 0.005 & 0.003 & 0.004 & 0.003 & 0.001 & 0.001 & 0.002 & 0.009 & 0.01 & 0.006 & 0.005 & 0.004 & 0.005 \\
\hline$\beta$-alanine & ND & $\mathrm{ND}$ & ND & ND & $\mathrm{ND}$ & $\mathrm{ND}$ & 0.001 & 0.001 & ND & $\mathrm{ND}$ & $\mathrm{ND}$ & ND & ND & ND & ND & ND & $\mathrm{ND}$ & ND \\
\hline$\beta$-Aminoisobutyric acid & 0.049 & 0.033 & 0.041 & 0.039 & 0.051 & 0.045 & 0.052 & 0.041 & 0.044 & 0.037 & 0.035 & 0.041 & 0.088 & 0.094 & 0.055 & 0.082 & 0.047 & 0.073 \\
\hline -Aminobutyric acid & 0.014 & 0.009 & 0.013 & 0.012 & 0.017 & 0.015 & 0.017 & 0.014 & $\mathrm{ND}$ & $\mathrm{ND}$ & $\mathrm{ND}$ & 0.002 & 0.033 & 0.033 & 0.003 & $\mathrm{ND}$ & ND & $\mathrm{ND}$ \\
\hline Histidine & 0.002 & 0.002 & 0.002 & 0.002 & 0.002 & 0.002 & 0.002 & 0.002 & 0.002 & 0.002 & 0.002 & 0.002 & 0.004 & 0.004 & 0.002 & 0.001 & 0.001 & 0.001 \\
\hline Ornithine & 0.001 & 0.001 & 0.001 & 0.001 & 0.001 & 0.001 & 0.001 & 0.001 & 0.001 & 0.001 & 0.001 & 0.001 & 0.002 & 0.002 & 0.001 & 0.001 & 0.001 & 0.001 \\
\hline Lysine & 0.021 & 0.016 & 0.018 & 0.017 & 0.023 & 0.021 & 0.020 & 0.017 & 0.014 & 0.01 & 0.01 & 0.007 & 0.033 & 0.032 & 0.008 & 0.005 & 0.003 & 0.002 \\
\hline Ammonia & 0.001 & 0.001 & 0.001 & 0.001 & 0.002 & 0.002 & ND & ND & ND & ND & ND & ND & 0.001 & 0.001 & $\mathrm{ND}$ & ND & $\mathrm{ND}$ & $\mathrm{ND}$ \\
\hline Arginine & 0.014 & 0.007 & 0.010 & 0.009 & 0.013 & 0.012 & 0.009 & 0.008 & 0.005 & ND & ND & ND & 0.019 & 0.019 & ND & ND & ND & ND \\
\hline Total & 0.189 & 0.134 & 0.171 & 0.16 & 0.218 & 0.195 & 0.185 & 0.156 & 0.102 & 0.075 & 0.071 & 0.078 & 0.444 & 0.452 & 0.16 & 0.152 & 0.091 & 0.132 \\
\hline
\end{tabular}

${ }^{1)} \mathrm{pH} 4$, initial acidity; $20^{\circ} \mathrm{C}$, fermentation temperature

${ }^{2)} \mathrm{ND}$, not detected. 
Table 6. The volatile compound according to fermentation period of Kujippong vinegar by optimum conditions using Acetobacter pasteurianus A26

(Unit : Area\%)

\begin{tabular}{|c|c|c|c|c|c|c|}
\hline \multirow{2}{*}{ Compounds } & \multicolumn{6}{|c|}{$\mathrm{pH} 4,20^{\circ} \mathrm{C}$} \\
\hline & 0 & 6 & 12 & 18 & 24 & 30 \\
\hline Acetic acid ethyl ester & $7.12 \pm 1.51^{(2)}$ & $7.10 \pm 1.11^{\mathrm{c}}$ & $28.45 \pm 1.70^{\mathrm{ab}}$ & $35.61 \pm 11.45^{\mathrm{a}}$ & $24.99 \pm 1.97^{b}$ & $20.77 \pm 2.00^{b}$ \\
\hline 1,1-Diethoxyethane & $2.06 \pm 0.52^{\mathrm{a}}$ & $\mathrm{ND}^{3)}$ & $\mathrm{ND}$ & ND & $\mathrm{ND}$ & ND \\
\hline Ethanol & $31.34 \pm 0.86^{\mathrm{ab}}$ & $35.66 \pm 1.52^{\mathrm{a}}$ & $25.33 \pm 2.93^{\mathrm{bc}}$ & $14.21 \pm 4.97^{\mathrm{d}}$ & $21.59 \pm 3.71^{\mathrm{c}}$ & $24.10 \pm 4.77^{\mathrm{c}}$ \\
\hline Propyl acetate & ND & ND & ND & ND & ND & ND \\
\hline Isobutyl acetate & ND & ND & ND & ND & ND & ND \\
\hline 2-Methyl-1-propanol & $1.73 \pm 0.13^{\mathrm{a}}$ & $1.31 \pm 0.34^{\mathrm{b}}$ & $1.02 \pm 0.22^{b c}$ & $0.59 \pm 0.18^{\mathrm{d}}$ & $0.90 \pm 0.19^{\mathrm{cd}}$ & $0.56 \pm 0.12^{\mathrm{d}}$ \\
\hline 3-Methyl butyl acetate & ND & $\mathrm{ND}$ & $\mathrm{ND}$ & $\mathrm{ND}$ & ND & ND \\
\hline 1-Butanol & ND & ND & ND & ND & ND & ND \\
\hline 3-Methyl-1-butanol & $13.55 \pm 0.86^{\mathrm{a}}$ & $12.87 \pm 2.87^{\mathrm{a}}$ & $8.72 \pm 0.58^{b}$ & $5.23 \pm 1.02^{\mathrm{c}}$ & $7.04 \pm 0.96^{b c}$ & $5.77 \pm 0.37^{\mathrm{bc}}$ \\
\hline Octanal & $0.28 \pm 0.03^{\mathrm{a}}$ & $0.22 \pm 0.06^{\mathrm{ab}}$ & $0.21 \pm 0.05^{\mathrm{ab}}$ & $0.11 \pm 0.04^{\mathrm{b}}$ & $0.24 \pm 0.04^{\mathrm{a}}$ & $0.18 \pm 0.12^{\mathrm{ab}}$ \\
\hline Nonanal & $0.71 \pm 0.04^{\mathrm{a}}$ & $0.81 \pm 0.16^{\mathrm{a}}$ & $0.76 \pm 0.34^{\mathrm{a}}$ & $0.39 \pm 0.21^{\mathrm{a}}$ & $0.56 \pm 0.15^{\mathrm{a}}$ & $0.59 \pm 0.28^{\mathrm{a}}$ \\
\hline 2-Ethylhexanol & $2.33 \pm 0.26^{\mathrm{a}}$ & $2.47 \pm 0.33^{\mathrm{a}}$ & $1.99 \pm 0.14^{\mathrm{a}}$ & $1.37 \pm 0.30^{b}$ & $2.05 \pm 0.16^{\mathrm{a}}$ & $2.04 \pm 0.36^{\mathrm{a}}$ \\
\hline Decanal & $0.90 \pm 0.15^{\mathrm{a}}$ & $2.16 \pm 0.45^{\mathrm{a}}$ & $1.83 \pm 0.94^{\mathrm{a}}$ & $0.98 \pm 0.47^{\mathrm{a}}$ & $1.90 \pm 0.86^{\mathrm{a}}$ & $1.61 \pm 0.96^{\mathrm{a}}$ \\
\hline 2-Hydroxy benzoic acid methyl ester & $13.61 \pm 0.97^{\mathrm{a}}$ & $7.38 \pm 0.87^{\mathrm{c}}$ & $5.78 \pm 0.27^{\mathrm{cd}}$ & $4.55 \pm 1.19^{\mathrm{d}}$ & $9.93 \pm 1.28^{\mathrm{b}}$ & $9.50 \pm 1.45^{\mathrm{b}}$ \\
\hline
\end{tabular}

${ }^{1)} \mathrm{pH} 4$, initial acidity; $20^{\circ} \mathrm{C}$, fermentation temperature.

${ }^{2)}$ Means \pm SD. Different letters in the same row are significantly different $(\mathrm{p}<0.05)$ by duncan's multiple range test.

${ }^{3)} \mathrm{ND}$, not detected.

Table 7. The volatile compound according to fermentation period of Kujippong vinegar by optimum conditions using Acetobacter pasteurianus A37

(Unit : Area\%)

\begin{tabular}{|c|c|c|c|c|c|c|}
\hline \multirow{2}{*}{ 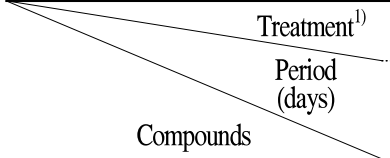 } & \multicolumn{6}{|c|}{$\mathrm{pH} 4,20^{\circ} \mathrm{C}$} \\
\hline & 0 & 6 & 12 & 18 & 24 & 30 \\
\hline Acetic acid ethyl ester & $16.03 \pm 0.88^{(2)}$ & $11.70 \pm 0.45^{\mathrm{c}}$ & $59.37 \pm 1.94^{b}$ & $72.07 \pm 4.74^{\mathrm{a}}$ & $67.54 \pm 3.04^{\mathrm{a}}$ & $59.18 \pm 2.60^{\mathrm{b}}$ \\
\hline 1,1-Diethoxyethane & $\mathrm{ND}^{3)}$ & $\mathrm{ND}$ & $\mathrm{ND}$ & $\mathrm{ND}$ & $\mathrm{ND}$ & $\mathrm{ND}$ \\
\hline Ethanol & $26.86 \pm 0.44^{a}$ & $27.53 \pm 3.25^{\mathrm{a}}$ & $12.53 \pm 1.21^{b}$ & $3.88 \pm 0.16^{\mathrm{c}}$ & $2.29 \pm 0.19^{c}$ & $1.47 \pm 0.13^{\mathrm{c}}$ \\
\hline Propyl acetate & ND & $\mathrm{ND}$ & $0.18 \pm 0.02^{\mathrm{b}}$ & $0.31 \pm 0.08^{\mathrm{a}}$ & $0.31 \pm 0.04^{\mathrm{a}}$ & $0.29 \pm 0.02^{\mathrm{a}}$ \\
\hline Isobutyl acetate & $\mathrm{ND}$ & ND & $0.27 \pm 0.06^{\mathrm{b}}$ & $1.07 \pm 0.20^{\mathrm{a}}$ & $1.00 \pm 0.29^{\mathrm{a}}$ & $0.84 \pm 0.11^{\mathrm{a}}$ \\
\hline 2-Methyl-1-propanol & $1.40 \pm 0.05^{\mathrm{a}}$ & $1.48 \pm 0.14^{\mathrm{a}}$ & $0.75 \pm 0.08^{b}$ & $0.48 \pm 0.03^{\mathrm{c}}$ & $0.64 \pm 0.06^{b}$ & $0.63 \pm 0.06^{b}$ \\
\hline 3-Methyl butyl acetate & $\mathrm{ND}$ & $\mathrm{ND}$ & $0.73 \pm 0.29^{b}$ & $2.79 \pm 0.68^{\mathrm{a}}$ & $2.43 \pm 1.12^{\mathrm{a}}$ & $2.27 \pm 0.39^{\mathrm{a}}$ \\
\hline 1-Butanol & ND & $\mathrm{ND}$ & $\mathrm{ND}$ & $\mathrm{ND}$ & $\mathrm{ND}$ & $\mathrm{ND}$ \\
\hline 3-Methyl-1-butanol & $10.32 \pm 0.04^{\mathrm{a}}$ & $10.70 \pm 1.08^{\mathrm{a}}$ & $5.94 \pm 0.53^{\mathrm{b}}$ & $3.84 \pm 0.20^{\mathrm{d}}$ & $5.51 \pm 0.41^{\mathrm{bc}}$ & $4.75 \pm 0.47^{\text {cd }}$ \\
\hline Octanal & $0.33 \pm 0.01^{\mathrm{b}}$ & $0.86 \pm 0.06^{\mathrm{a}}$ & $0.23 \pm 0.05^{\mathrm{c}}$ & $0.13 \pm 0.02^{\mathrm{d}}$ & $0.13 \pm 0.00^{\mathrm{d}}$ & $0.27 \pm 0.02^{\mathrm{bc}}$ \\
\hline Nonanal & $0.76 \pm 0.05^{b}$ & $1.55 \pm 0.20^{\mathrm{a}}$ & $0.50 \pm 0.13^{\mathrm{c}}$ & $0.34 \pm 0.04^{\text {cd }}$ & $0.25 \pm 0.03^{\mathrm{d}}$ & $0.55 \pm 0.14^{\mathrm{bc}}$ \\
\hline 2-Ethylhexanol & $1.84 \pm 0.09^{b}$ & $2.38 \pm 0.33^{\mathrm{a}}$ & $1.17 \pm 0.05^{\mathrm{c}}$ & $0.84 \pm 0.06^{d}$ & $0.98 \pm 0.08^{\mathrm{cd}}$ & $1.27 \pm 0.22^{\mathrm{c}}$ \\
\hline Decanal & $1.74 \pm 0.01^{\mathrm{b}}$ & $2.67 \pm 0.26^{\mathrm{a}}$ & $0.90 \pm 0.23^{\mathrm{c}}$ & $0.65 \pm 0.28^{c}$ & $0.50 \pm 0.05^{\mathrm{c}}$ & $1.43 \pm 0.37^{b}$ \\
\hline 2-Hydroxy benzoic acid methyl ester & $11.87 \pm 0.27^{\mathrm{a}}$ & $1.96 \pm 0.24^{\mathrm{bc}}$ & $2.68 \pm 0.42^{\mathrm{bc}}$ & $2.82 \pm 1.71^{\mathrm{bc}}$ & $3.27 \pm 0.14^{\mathrm{b}}$ & $1.58 \pm 0.21^{\mathrm{c}}$ \\
\hline
\end{tabular}

${ }^{1)} \mathrm{pH} 4$, initial acidity; $20^{\circ} \mathrm{C}$, fermentation temperature.

${ }^{2)}$ Means \pm SD. Different letters in the same row are significantly different $(\mathrm{p}<0.05)$ by duncan's multiple range test.

${ }^{3} \mathrm{ND}$, not detected. 
다음으로 검출된 lactic acid는 식초제조를 위한 당질의 알코올 발효 초기 젖산균이 번식하여 생성된 것이라 판단하 며(30), citric acid, succinic acid 순으로 나타났다. A26 초산 균은 발효 종료 시 citric acid $4.64 \mathrm{mg} / \mathrm{mL}$ 로 가장 높았는데, 이는 Lee와 $\operatorname{Kim}(31)$ 의 꾸지뽕 열매의 유기산 함량을 분석 한 결과, citric acid, succinic acid가 다량 검출되었다는 보고 를 바탕으로 본 연구에서 원료로 사용한 꾸지뽕 열매 자체 의 유기산 구성에 영향 또는 젖산발효가 진행된 것으로 여겨진다.

\section{꾸지뽕 발효식초의 유리 아미노산 변화}

식초의 유리 아미노산은 구성 성분에 따라 맛에 영향을 미친다고 알려져 있다(32). 3종류 초산균을 이용하여 발효 기간별 제조한 꾸지뽕 식초의 유리아미노산 분석 결과를 Table 5에 나타내었다. 꾸지뽕 열매로 초산 발효물의 이화 학적 특성 분석 결과를 바탕으로 최적의 발효조건 $(\mathrm{pH} 4$, $20^{\circ} \mathrm{C}$ )에서 각 균주별로 제조한 꾸지뽕 식초의 유리 아미노 산 함량을 분석한 결과, 초산균 종류와 상관없이 공통적으 로 $\beta$-aminoisobutyric acid, phosphoserine 등이 주요한 아미 노산으로 검출되었다, $\mathrm{A} 37$ 초산균으로 빚은 꾸지뽕 식초는 $\beta$-aminoisobutyric aicd $(0.041 \mathrm{mg} / \mathrm{mL})$, phosphoserine $(0.012$ $\mathrm{mg} / \mathrm{mL})$, lysine $(0.007 \mathrm{mg} / \mathrm{mL})$, cystine $(0.004 \mathrm{mg} / \mathrm{mL})$ 순으 로, B7 초산균은 $\beta$-aminoisobutyric $\operatorname{acid}(0.078 \mathrm{mg} / \mathrm{mL})$, phosphoserine $(0.027 \mathrm{mg} / \mathrm{mL})$, cystine $(0.007 \mathrm{mg} / \mathrm{mL})$ 순으로 분포되었으며, 산미를 온화하게 해주는 glutamic $\operatorname{acid}(0.005$ $\mathrm{mg} / \mathrm{mL}$ ) 또한 확인되었다(33).

초산균 종류별 제조한 꾸지뽕 식초의 총 유리 아미노산 함량은 $A$ pasteurianus A26 초산균 $(0.195 \mathrm{mg} / \mathrm{mL})>$ $\mathrm{B} 7(0.132 \mathrm{mg} / \mathrm{mL})>\mathrm{A} 37(0.078 \mathrm{mg} / \mathrm{mL})$ 순으로 산 생성능이 우수한 균주가 비교적 낮은 함량을 나타내며 발효가 진행될 수록 감소하였다. 이러한 결과는 원료에서 유래된 아미노 산이 초산발효 중 자화되어 $38-60 \%$ 가 감소된다는 보고 결 과와 유사한 경향을 나타내었다(34).

\section{꾸지뽕 발효식초의 휘발성 향기성분 변화}

일반적으로 식초의 향미는 원료, 발효방법, 숙성 등의 과정을 거치면서 발효 미생물의 작용으로 초산 이외의 acid, aldehyde, alcohol, ketone 및 ester류 화합물이 상호 복합적으 로 작용하여 다양한 종류의 휘발성 성분이 생성된다(35). 3종류 초산균을 이용하여 최적 발효조건에서 발효기간별 제조한 꾸지뽕 식초의 휘발성 향기성분 분석 결과를 Table 6-8에 나타내었다.

최적 발효조건인 초기 산도 $\mathrm{pH} 4$ 와 발효온도 $20^{\circ} \mathrm{C}$ 에서 제조한 꾸지뽕 식초 중 산도가 가장 높게 나타난 A37 초산 균은 휘발성 성분이 12 종 검출되어 사용한 3 종류의 초산균 중 가장 다양한 성분을 가지고 있었다. 꾸지뽕 식초의 발효

Table 8. The volatile compound according to fermentation period of Kujippong vinegar by optimum conditions using Acetobacter pasteurianus $\mathrm{B} 7$

(Unit : Area\%)

\begin{tabular}{|c|c|c|c|c|c|c|}
\hline \multirow{2}{*}{ Compounds } & \multicolumn{6}{|c|}{$\mathrm{pH} 4,20^{\circ} \mathrm{C}$} \\
\hline & 0 & 6 & 12 & 18 & 24 & 30 \\
\hline Acetic acid ethyl ester & $4.22 \pm 0.76^{(2)}$ & $1.89 \pm 0.22^{\mathrm{e}}$ & $7.99 \pm 2.59^{\mathrm{d}}$ & $22.60 \pm 0.93^{c}$ & $28.18 \pm 3.92^{b}$ & $37.53 \pm 1.31^{\mathrm{a}}$ \\
\hline 1,1-Diethoxyethane & $1.98 \pm 0.51^{\mathrm{a}}$ & $0.76 \pm 0.20^{b}$ & $\mathrm{ND}^{3)}$ & $\mathrm{ND}$ & $\mathrm{ND}$ & $\mathrm{ND}$ \\
\hline Ethanol & $32.41 \pm 5.43^{\mathrm{a}}$ & $10.17 \pm 8.52^{\mathrm{b}}$ & $27.96 \pm 2.89^{\mathrm{a}}$ & $15.56 \pm 3.19^{b}$ & $10.66 \pm 0.77^{b}$ & $9.37 \pm 0.97^{b}$ \\
\hline Propyl acetate & $\mathrm{ND}$ & $\mathrm{ND}$ & $\mathrm{ND}$ & $\mathrm{ND}$ & $\mathrm{ND}$ & $\mathrm{ND}$ \\
\hline Isobutyl acetate & $\mathrm{ND}$ & $\mathrm{ND}$ & $\mathrm{ND}$ & $\mathrm{ND}$ & $\mathrm{ND}$ & $\mathrm{ND}$ \\
\hline 2-Methyl-1-propanol & $1.24 \pm 0.19^{\mathrm{a}}$ & $0.75 \pm 0.10^{b}$ & $1.12 \pm 0.33^{\mathrm{ab}}$ & $1.12 \pm 0.21^{\mathrm{ab}}$ & $1.12 \pm 0.11^{\mathrm{ab}}$ & $1.29 \pm 0.14^{\mathrm{a}}$ \\
\hline 3-Methyl butyl acetate & $\mathrm{ND}$ & $\mathrm{ND}$ & $\mathrm{ND}$ & $\mathrm{ND}$ & $\mathrm{ND}$ & $\mathrm{ND}$ \\
\hline 1-Butanol & $0.17 \pm 0.04^{\mathrm{a}}$ & $0.08 \pm 0.04^{\mathrm{a}}$ & $0.16 \pm 0.04^{\mathrm{a}}$ & $0.13 \pm 0.12^{\mathrm{a}}$ & $0.11 \pm 0.02^{\mathrm{a}}$ & $0.13 \pm 0.02^{\mathrm{a}}$ \\
\hline 3-Methyl-1-butanol & $12.43 \pm 0.38^{\mathrm{a}}$ & $7.47 \pm 1.87^{b}$ & $10.12 \pm 1.66^{\mathrm{a}}$ & $11.68 \pm 1.18^{\mathrm{a}}$ & $9.89 \pm 1.37^{\mathrm{a}}$ & $11.52 \pm 1.06^{\mathrm{a}}$ \\
\hline Octanal & $0.32 \pm 0.24^{\mathrm{a}}$ & $0.22 \pm 0.05^{\mathrm{a}}$ & $0.26 \pm 0.11^{\mathrm{a}}$ & $0.15 \pm 0.03^{\mathrm{a}}$ & $0.13 \pm 0.06^{\mathrm{a}}$ & $0.25 \pm 0.04^{\mathrm{a}}$ \\
\hline Nonanal & $0.85 \pm 0.55^{\mathrm{ab}}$ & $0.67 \pm 0.14^{\mathrm{abc}}$ & $0.55 \pm 0.24^{\mathrm{abc}}$ & $0.42 \pm 0.11^{\mathrm{bc}}$ & $0.25 \pm 0.05^{\mathrm{c}}$ & $1.01 \pm 0.16^{\mathrm{a}}$ \\
\hline 2-Ethylhexanol & $2.37 \pm 0.28^{\mathrm{ab}}$ & $1.26 \pm 0.21^{\mathrm{c}}$ & $1.66 \pm 0.29^{c}$ & $2.60 \pm 0.54^{\mathrm{a}}$ & $1.79 \pm 0.44^{\mathrm{bc}}$ & $2.31 \pm 0.04^{\mathrm{ab}}$ \\
\hline Decanal & $1.62 \pm 0.70^{\mathrm{a}}$ & $0.85 \pm 0.20^{\mathrm{ab}}$ & $1.04 \pm 0.63^{\mathrm{ab}}$ & $0.60 \pm 0.22^{b}$ & $0.43 \pm 0.05^{b}$ & $1.24 \pm 0.41^{\mathrm{ab}}$ \\
\hline 2-Hydroxy benzoic acid methyl ester & $6.16 \pm 2.38^{\mathrm{cd}}$ & $3.99 \pm 0.36^{\mathrm{d}}$ & $10.59 \pm 2.18^{b}$ & $15.84 \pm 0.90^{\mathrm{a}}$ & $7.60 \pm 1.34^{\mathrm{c}}$ & $6.82 \pm 0.23^{c}$ \\
\hline
\end{tabular}

${ }^{1)} \mathrm{pH} 4$, initial acidity; $20^{\circ} \mathrm{C}$, fermentation temperature.

${ }^{2}$ Means \pm SD. Different letters in the same row are significantly different $(p<0.05)$ by duncan's multiple range test.

${ }^{3} \mathrm{ND}$, not detected. 
기간별 향기성분 중에서 산 생성능이 우수한 $A$ pasteurianus $\mathrm{A} 37(6.3 \%)$ 과 $\mathrm{B} 7$ 초산균(6.1\%)의 acetic acid, ethyl ester는 A37 초산균은 발효 18일에 $72.07 \%$ 를, B7 초산 균에서 발효 30 일에 $37.53 \%$ 로 가장 높게 나타났다. 이는 자극취를 나타내는 산미로서 초산균에 의해 생성되는 산화 생성물로 식초의 주된 휘발성 성분으로 나타났다 $(36,37)$. 식초는 원료의 고유 특성으로 인한 맛과 향기성분을 가지는 동시에 발효 및 숙성방법에 따라 향기성분의 차이가 나타난 다(38). 따라서 본 연구에서 동일한 원료를 사용하였지만 검출된 휘발성분이 각각 다른 것은 사용한 초산균과 발효조 건에 따른 차이로 볼 수 있었다.

초산 생성능이 낮은 $\mathrm{A} 26$ 초산균의 휘발성 성분인 acetic acid, ethyl ester는 발효시간이 경과할수록 줄어들었고 상대 적으로 ethanol은 $24.1 \%$ (30일)로 가장 높게 나타났다. $A$ pasteurianus $\mathrm{A} 37$ 과 $\mathrm{B} 7$ 초산균으로 제조한 꾸지뽕 발효식 초는 acetic acid ethyl ester, 3-methyl-1-butanol(isoamyl alcohol), 2-hydroxy benzoic acid(salicylic acid), ethanol, decanal, 그리고 2-ethylhexanol 등의 다양한 휘발성분을 가 지고 있어 발효식초의 풍미에 영향을 미친다.

\section{요 약}

본 연구에서는 3 종류의 초산균(A26, A37, B7)에 따른 꾸지뽕 발효식초의 최적 제조조건과 품질 특성을 규명하고 자 하였다. 따라서 초기 산도 $(\mathrm{pH} 2,3,4)$ 와 발효온도( 20 , $30,35^{\circ} \mathrm{C}$ )를 달리하여 꾸지뽕 발효식초를 제조한 결과, $A$ pasteurianus $\mathrm{A} 37$ 과 $\mathrm{B} 7$ 초산균 모두 $\mathrm{pH} 4,20^{\circ} \mathrm{C}$ 발효조건에 서 초산 생성능이 우수하였다. 이들 식초의 $\mathrm{pH}$ 및 적정산도 를 분석한 결과, 발효 종료 시(30일) A37 초산균은 $\mathrm{pH} 2.45$,

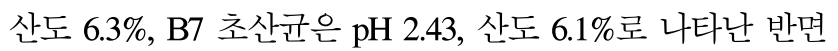
에 $\mathrm{A} 26$ 초산균은 모든 시험구에서 초산 생성이 낮게 나타났 다. 초산 생성능이 우수한 조건 $\left(\mathrm{pH} 4,20^{\circ} \mathrm{C}\right)$ 에서 제조한 꾸지뽕 발효식초의 유기산을 분석한 결과, 발효 종료 시 0 일차로부터 약 10 배 정도 증가하였으며 주요 유기산인 acetic acid는 A37 초산균에서 $37.34 \mathrm{mg} / \mathrm{mL}$, 그리고 B7은 $39.34 \mathrm{mg} / \mathrm{mL}$ 로 나타났다. 휘발성 향기성분 변화를 조사한 결과, $A$ pasteurianus $\mathrm{A} 37, \mathrm{~B} 7$ 초산균에서 비교적 다양한 종류의 휘발성 성분을 가지는데 주요 휘발성 성분으로 acetic acid ethyl ester가 각 $59.18 \%$ 와 $37.53 \%$ 함량을 가지고 있었다. 기능성이 뛰어난 국산 농·특산물의 소비 촉진을 위해, 꾸지뽕 열매를 이용한 농가형 발효식초의 현장 실용 화로 농가 소득 증진에 기여하고자 한다.

\section{감사의 글}

이 논문은 농촌진흥청 농업과학기술개발사업(과제번호:
PJ01258801)의 지원에 의해 이루어진 것이며, 연구비 지원 에 감사드립니다.

\section{References}

1. Mok CK (2005) Quality characteristics of instant tea prepared from spray-dried Omija (Schizandra chinensis Baillon) extract grape juice mixture. Food Engineer Progress, 9, 226-230

2. Park MS, Rim YS, Shin SC (2006) Comparison of the properties and extracting conditions of juice preparation from Schizandra nigar. J Korean Forestry Sci, 95, 453-485

3. Jo JS (1984) The types and characteristics of vinegar. Korean J Food Sci Technol, 17, 38-60

4. Jeong YJ (2009) Current trends and future prospects in the Korean vinegar industry. Food Sci Ind, 42, 52-59

5. Lee JS, Lee MG, Lee SW (1989) A study on the general components and minerals in parts of omija (Schizandra chinensis Ballon). Korean J Dietary Culture, 4, 173-176

6. Kwon YS, Park BR, Lee S, Yu HC, Beak SJ, Oh CJ (2014) A study on the morphological characteristics of leaves and fruit of Cudrania tricuspidata in korea. Korean J Plant Res, 27, 337-343

7. Jung GT, Ju IO, Choi SR, You DH, Noh JJ (2013) Food nutritional characteristics of fruit of Cudrania tricuspidata in its various maturation stages. Korean $\mathrm{J}$ Food Preserv, 20, 330-335

8. Kang DH, Kim JW, Youn KS (2011) Antioxidant activities of extracts from fermented mulberry (Cudrania tricuspidata) fruit, and inhibitory actions on elastase and tyrosinase. Korean J Food Preserv, 18, 236-243

9. Do GP, Lee HJ, Do JR, Kim HK (2011) Inhibition of adipogenesis in 3T3-L1 adipocytes with waster and ethanol extracts of Cudrania tricuspidata leaves. Korean J Food Preserv, 18, 244-249

10. Choi SR, Ju IO, Jang I, Ryu J (2007) Antioxidant and antimicrobial activity by harvesting organs in Cudrania tricuspidata. Korean Soc Med Crop Sci, May, Academic processing A-13 66-67

11. Chen F, Nakashima N, Kimura I, Kumura M (1995) Hypoglycemic activity and mechanisms of extracts from mulberry leaves (Folium mori) and cortex mori radicis ing streptozotocin-induced diabetic mice. Yakugaku Zasshi, 115, 476-482

12. Ottersen T, Vance B, Doorenbos NJ, Chang BL, el-Feraly 
FS (1997) The crystal structure of cudranone, 2,6,3' -trihydroxy-4-methoxy-2 ' -(3-methyl-2-butenyl)benzophenone: a new antimicrobial agent from Cudrania chochinchinensis. Acta Chem Scand B, 31, 434-436

13. Youn KS, Kim JW (2012) Antioxidant angiotensin converting enzyme I inhibitory activities of extracts from mulberry (Cudrania tricuspidata) fruit subjected to different drying methods. J Korean Soc Food Sci Nutr, 41, 1388-1394

14. Cha JY, Cho YS (2001) Antioxidative activity extracts from fruit of Cudrania tricuspidata. J Korean Soc Food Sci Nutr, 30, 547-551

15. Nomura T, Hano Y, Fujimoto $T$ (1983) Three new isoprenylated xanthones, cudraxanthone $\mathrm{A}, \mathrm{B}$ and $\mathrm{C}$, from the root barks of Cudrania tricuspidata. Hetrocycles, 20, 213-218

16. Park JC, Young HS, Choi JS (1992) Constituents of Cudrania tricuspidata in Korea. Yakhak Hoeji, 36, 40-45

17. Yoon HH, Chae KS, Son RH, Jung JH (2015) Antioxidant activity and fermentation characteristics of blueberry wine using traditional yeast. J Korean Soc Food Sci Nutr, 44, 840-846

18. Beak CH, Jeong DH, Beak SY, Choi JH, Park HY, Choi HS, Jeong ST, Kim JH, Jeong YJ, Kwon JH, Yeo SH (2013) Quality characteristics of farm-made brown rice vinegar via traditional static fermentation. Korean J Food Preserv, 20, 564-572

19. Park YO (2018) Quality comparison of natural fermented vinegars manufactured with different raw materials. J Korean Soc Food Sci Nutr, 47, 46-54

20. Jeong EJ, Jeon SY, Beak JH, Cha YJ (2011) Volatile flavor compounds in commercial vinegar beverages derived from fruits. J Life Science, 21, 292-299

21. Kim HJ, Park SH, Park CH (1985) Studies on the production of vinegar from barley. Korean J Food Sci Technol, 17, 350-354

22. Sung NH, Woo SM, Kwon JH, Yeo SH, Jeong YJ (2014) Quality characteristics of high acidity apple vinegar manufactured using two stage fermentation. J Korean Soc Food Sci Nutr, 43, 877-883

23. Jang SY, Sin KA, Jeong YJ (2010) Quality characteristics of apple vinegar by agitated and static cultures. J Korean Soc Food Sci Nutr, 39, 308-312

24. Jo D, Park EJ, Kim GR, Yeo SH, Jeong YJ, Kwon JH (2012) Quality comparison of commercial cider vinegars by their acidity levels. Korean J Food Sci Technol, 44, 699-703
25. Kim YD, Kang SH, Kang SK (1996) Studies on the acetic acid fermentation using maesil juice. J Korean Soc Food Sci Nutr, 25, 695-700

26. Nakanc S (1988) Food useful for preventing alcohol in toxication containing persimmon-vinegar and optimum fruits, with blood alcohol concentration reducing action. Japan Patent, 63, 562-566

27. Jeong YJ, Seo JH, Lee GD, Park NY, Choi TH (1999) The quality comparison of apple vinegar by two stages fermentation with commercial apple vinegar. J Korean Soc Food Sci Nutr, 28, 353-358

28. Kim KO, Kim SM, Kim SM, Kim DY, Jo DJ, Yeo SH, Jeong YJ, Kwon JH (2013) Physicochemical properties of commercial fruit vinegars with different fermentation methods. J Korean Soc Food Sci Nutr, 42, 736-742

29. Ko HS (2017) Development of functional vinegar using Cudrania tricuspidata Bureau and Rudbeckia laciniata var. hortensis, and their quality characteristics. MS Thesis, Mokpo National University, Korea. p 23

30. Kim CJ, Park YJ, Lee SK, Oh MJ (1981) Studies on the induction of available mutant of acetic acid bacteria by UV-light irradiation and NTG treatment. Microbiol. Biotechnol. Lett, 9, 139-143

31. Lee HK, Kim YS (2015) Comparison of proximate composition of Cudrania tricuspidata Bureau fruit. $\mathbf{J}$ Agric Life Sci, 46, 22-26

32. Jeong YJ, Lee MH (2000) A view and prospect of vinegar industry. Food Ind Ntur, 5, 7-12

33. Lee YC, Jang OY, Kim HW, Choi CU, Yoon SK (1999) Physicochemical characteristics of traditional vinegars in Andong province. Korean J Dietary Culture, 14, 17-20

34. Yukimichi K, Yasuhiro U, Fujiharu Y (1987) The general composition inorganic cations free amino acids and organic acid of special vinegars. Nippon Shokuhin Kogyo Gakkaishi, 34, 592-596

35. Beak SY, Kim JS, Mun JY, Lee CH, Park YK, Yeo SH (2016) Quality characteristics of detoxified Rhus verniciflua vinegar fermented using different acetic acid bacteria. Korean J Food Preserv, 23, 347-354

36. Su MS, Chein PJ (2010) Aroma impact components of rabbiteye blueberry (Vaccinium ashe1) vinegars. Food Chem, 119, 923-928

37. Tasfaye W, Garcia-parrilla MC, Troncoso AM (2002) Sensory evaluation of sherry wine vinegar. Journal of Sensoy Studies, 17, 133-144

38. Jeoung YJ, Lee MH (2000) A view and prospect of vinegar industry. Food Ind Nutr, 5, 7-12 